\title{
Specificity of Primate Amygdalar Pathways to Hippocampus
}

\author{
이ingyi Wang ${ }^{1}$ and ${ }^{\circ}$ Helen Barbas ${ }^{1,2}$ \\ ${ }^{1}$ Neural Systems Laboratory, Department of Health Sciences, Boston University, Boston, Massachusetts 02215, and ${ }^{2}$ Graduate Program in Neuroscience, \\ Boston University and School of Medicine, Boston, Massachusetts 02215
}

The amygdala projects to hippocampus in pathways through which affective or social stimuli may influence learning and memory. We investigated the still unknown amygdalar termination patterns and their postsynaptic targets in hippocampus from system to synapse in rhesus monkeys of both sexes. The amygdala robustly innervated the stratum lacunosum-moleculare layer of cornu ammonis fields and uncus anteriorly. Sparser terminations in posterior hippocampus innervated the radiatum and pyramidal layers at the prosubicular/CA1 juncture. The terminations, which were larger than other afferents in the surrounding neuropil, position the amygdala to influence hippocampal input anteriorly, and its output posteriorly. Most amygdalar boutons (76-80\%) innervated spines of excitatory hippocampal neurons, and most of the remaining innervated presumed inhibitory neurons, identified by morphology and label with parvalbumin or calretinin, which distinguished nonoverlapping neurochemical classes of hippocampal inhibitory neurons. In CA1, amygdalar axons innervated some calretinin neurons, which disinhibit pyramidal neurons. By contrast, in CA3 the amygdala innervated both calretinin and parvalbumin neurons; the latter strongly inhibit nearby excitatory neurons. In CA3, amygdalar pathways also made closely spaced dual synapses on excitatory neurons. The strong excitatory synapses in CA3 may facilitate affective context representations and trigger sharp-wave ripples associated with memory consolidation. When the amygdala is excessively activated during traumatic events, the specialized innervation of excitatory neurons and the powerful parvalbumin inhibitory neurons in CA3 may allow the suppression of activity of nearby neurons that receive weaker nonamygdalar input, leading to biased passage of highly charged affective stimuli and generalized fear.

Key words: calretinin neurons; electron microscopy; emotion; memory; parvalbumin neurons; PTSD

Significance Statement

Strong pathways from the amygdala targeted the anterior hippocampus, and more weakly its posterior sectors, positioned to influence a variety of emotional and cognitive functions. In hippocampal field CA1, the amygdala innervated some calretinin neurons, which disinhibit excitatory neurons. By contrast, in CA3 the amygdala innervated calretinin as well as some of the powerful parvalbumin inhibitory neurons and may help balance the activity of neural ensembles to allow social interactions, learning, and memory. These results suggest that when the amygdala is hyperactive during emotional upheaval, it strongly activates excitatory hippocampal neurons and parvalbumin inhibitory neurons in CA3, which can suppress nearby neurons that receive weaker input from other sources, biasing the passage of stimuli with high emotional import and leading to generalized fear.

\section{Introduction}

The amygdala, one of the key centers of the brain for emotions, influences learning and memory of salient events in hippocampus (LeDoux, 1992; Nader et al., 2000; Paré et al., 2002; Paré, 2003; Paz and Pare, 2013; Desmedt et al., 2015; Inman et al.,

\footnotetext{
Received May 17, 2018; revised Aug. 16, 2018; accepted Sept. 13, 2018.

Author contributions: J.W. and H.B. designed research; J.W. performed research; J.W. analyzed data; J.W. and H.B. wrote the paper.

This work was supported by National Institutes of Health/National Institute of Mental Health Grants R01-MH057414 and R01-MH-117785. We thank Drs. Y. John, M. Á. García-Cabezas and B. Zikopoulos for helpful discussions. The authors declare no competing financial interests.

Correspondence should be addressed to Helen Barbas, Boston University, 635 Commonwealth Avenue, Room 431, Boston, MA 02215. E-mail: barbas@bu.edu.

https://doi.org/10.1523/JNEUROSCl.1267-18.2018

Copyright $\odot 2018$ the authors $\quad 0270-6474 / 18 / 3810019-23 \$ 15.00 / 0$
}

2018). The neural basis of this process is likely mediated through pathways between the two structures, as shown in primates and rodents (Saunders et al., 1988; Cahill and McGaugh, 1998; Allsop et al., 2014; Felix-Ortiz and Tye, 2014; Redondo et al., 2014). The amygdala is one of only a few structures that has direct connections with the hippocampus, sharing privileged access with the entorhinal cortex, midline thalamic nuclei, and the septum in primates and rats (Witter and Amaral, 1991; Khakpai et al., 2013; Vertes et al., 2015; Eichenbaum, 2017).

The pathway from the amygdala to hippocampus has been studied extensively in rodents, but more sparsely in primates (Saunders et al., 1988; Pikkarainen et al., 1999; Pitkänen et al., 2000; Petrovich et al., 2001). In rats, nearly all amygdalar nuclei, except the central, project widely to hippocampus (Pikkarainen 
Table 1. Cases, tracers, and analyses

\begin{tabular}{|c|c|c|c|c|c|c|c|c|}
\hline \multirow[b]{2}{*}{ Case } & \multirow[b]{2}{*}{ Sex } & \multirow[b]{2}{*}{ Age (years) } & \multirow[b]{2}{*}{ Hemisphere } & \multirow[b]{2}{*}{ Injection site } & \multirow[b]{2}{*}{ Tracer } & \multicolumn{3}{|c|}{ Analysis } \\
\hline & & & & & & $\mathrm{BF}$ & $\mathrm{F}$ & EM \\
\hline BL & Male & 3 & Right & Cortical and basomedial nuclei & FR & $S$ & $A, B S$ & $M F, P, 3 D$ \\
\hline BM & Female & 3.5 & Right & Basolateral nucleus & FR & $A T, S$ & $A, B S$ & $M F, P$ \\
\hline BN & Male & 2 & Right & Basolateral and basomedial nuclei & $\mathrm{FE}$ & AT, S & $A, B S$ & $M F, P$ \\
\hline BT & Female & 4 & Right & Basolateral and basomedial nuclei & BDA & $A T, S$ & $A, B S$ & \\
\hline BJ & Female & 2 & Right & NAp & NAp & NAp & CBP & NAp \\
\hline BF & Female & $\mathrm{NAv}$ & Left & NAp & NAp & NAp & CBP & NAp \\
\hline $\mathrm{BH}$ & Female & 3 & Left & NAp & NAp & NAp & CBP & NAp \\
\hline $\mathrm{BI}$ & Female & 3 & Right & NAp & NAp & NAp & CBP & NAp \\
\hline
\end{tabular}

BF, Bright-field microscopy; F, fluorescent microscopy; A, appositions of presynaptic and postsynaptic sites with confocal microscopy; AT, axon tracing; BS, bouton size analysis with confocal microscopy; CBP, calcium binding protein; MF, morphological features using EM; P, postsynaptic targets identified with EM; S, stereology; NAv, not available; NAp, not applicable; 3D, three dimensional reconstruction.

et al., 1999; Pitkänen et al., 2000; Petrovich et al., 2001). By contrast, in primates the pathways are comparatively discrete: projections originate in the medial part of the amygdala and terminate focally in specific layers of the CA fields and the subicular complex (Saunders et al., 1988; Amaral and Lavenex, 2006).

Most functional studies, which showed that the CA1 and CA3 of hippocampal fields play distinct roles in contextual encoding and retrieval of memory (Lee and Kesner, 2004; Daumas et al., 2005; Koene and Hasselmo, 2008; Redondo et al., 2014; Strange et al., 2014; Bergstrom, 2016) were performed in rats and mice. Available studies in primates showed similar results (Bakker et al., 2008; Suthana et al., 2009; VanElzakker et al., 2014; Ito and Lee, 2016).

In view of the focal connections of the primate amygdala with functionally distinct regions of hippocampus, it is necessary to further probe this pathway, whose features remain largely unexplored, including the quantitative pattern of projections, the type and size of presynaptic terminals, and their regional and laminar targets in hippocampus. A key missing piece from the literature concerns both the types of inhibitory neurons in primate hippocampus, and their potential innervation by the amygdala. This information is needed because the hippocampal layers contain distinct segments of the pyramidal neurons, which have different roles in rhythmic activities (Kamondi et al., 1998; Megías et al., 2001; Amaral and Lavenex, 2006). These rhythms critically depend on inhibitory neurons that gate the flow of information, at least in rodents (Klausberger et al., 2003; Klausberger, 2009; Chamberland and Topolnik, 2012). To address this issue, it was necessary to first determine whether the neurochemical groups of inhibitory neurons that express one of the calcium-binding proteins in the primate cortex, namely calretinin (CR), parvalbumin (PV), or calbindin (CB; DeFelipe, 1997), are also expressed in the primate hippocampus.

We found that CR and PV reliably labeled nonoverlapping neurochemical classes of hippocampal inhibitory neurons in rhesus monkeys, and showed a regional and laminar distribution. We then probed the pattern of terminations in the amygdalarhippocampal pathway from the level of the system to the synapse and identified the postsynaptic sites innervated. We found that amygdalar terminations extend throughout the longitudinal axis of the hippocampus, but most were concentrated anteriorly. Moreover, there were differences in the pattern of inhibitory targets of the amygdala in CA1 and CA3, suggesting that the amygdala may exert different effects on the internal circuit dynamics and shifts in neural rhythms associated with emotional, mnemonic, and cognitive processes in hippocampus.

\section{Materials and Methods}

\section{Experimental design}

To investigate the pattern and postsynaptic targets of amygdalar terminations in the hippocampus, we injected tracers in the amygdala and systematically studied their axon terminations in different hippocampal subregions. We chose sites for injection within the medial third of the basal nuclei and adjacent cortical nuclei because of their robust connections with the hippocampus (Saunders et al., 1988). We used immunohistochemistry to label amygdalar terminations and different classes of inhibitory neurons in the hippocampus. We viewed pathways at the level of the system using light microscopy (LM) or fluorescence microscopy, and at the ultrastructural level using electron microscopy (EM). At the confocal and EM levels, we also studied the postsynaptic targets of amygdalar pathways. Table 1 lists the cases, tracers, and types of analyses conducted.

Using LM, we first delineated the architecture of the hippocampus to subdivide it into subregions and layers using series of coronal sections stained for Nissl and matched sections stained for acetylcholinersterase (AChE; see Fig. 1). Using the architecture as a guide, we then studied the overall topographic distribution of amygdalar terminations in the entire hippocampus. We then used unbiased stereology to quantitatively analyze the proportion of amygdalar boutons in each subregion and layer of the entire hippocampus in all cases with tracer injections. In matched series of sections, we studied the size of terminals at the confocal and EM levels in the hippocampal stratum lacunosum moleculare (SLM) layer of CA1 and CA3, chosen because the initial analysis showed that these sites were robustly innervated by the amygdala. To study potential inhibitory targets of the amygdala in hippocampus, it was necessary to first study the inhibitory microenvironment of the primate hippocampus. We addressed this issue by labeling for calcium-binding proteins, which distinguish nonoverlapping neurochemical classes of inhibitory neurons in the primate cortex (DeFelipe, 1997). After establishing that the neurochemical classes of PV and CR reliably label inhibitory neurons in the primate hippocampus, we double labeled pathways and PV or CR to study whether amygdalar pathways also innervate inhibitory hippocampal neurons. In anterior hippocampus, we studied appositions between labeled amygdalar axon boutons and the postsynaptic SLM layer of CA1 and CA3 hippocampal subregions using confocal microscopy. We then double labeled sections from the same subregions for EM to study synapses between amygdalar pathways and excitatory and inhibitory postsynaptic sites. Long series of EM sections made it possible to identify specialized features of amygdalar axon boutons and their postsynaptic targets on excitatory and inhibitory hippocampal neurons.

We used the two-tailed $t$ test for paired comparisons and ANOVA with Bonferroni's post hoc test for multiple comparisons, $\chi^{2}$ test for appositions, and linear regression to test the relationship between postsynaptic density (PSD) surface area and bouton volume or diameter.

Surgery, tracer injections, and perfusion

We studied amygdalar pathways after placing tracers in rhesus monkeys (Macaca mulatta; $n=4$; age range, $2-4$ years; 2 females; cases: BL, BM, $\mathrm{BN}$, and $\mathrm{BT})$. To study the types and regional distribution of inhibitory 
A

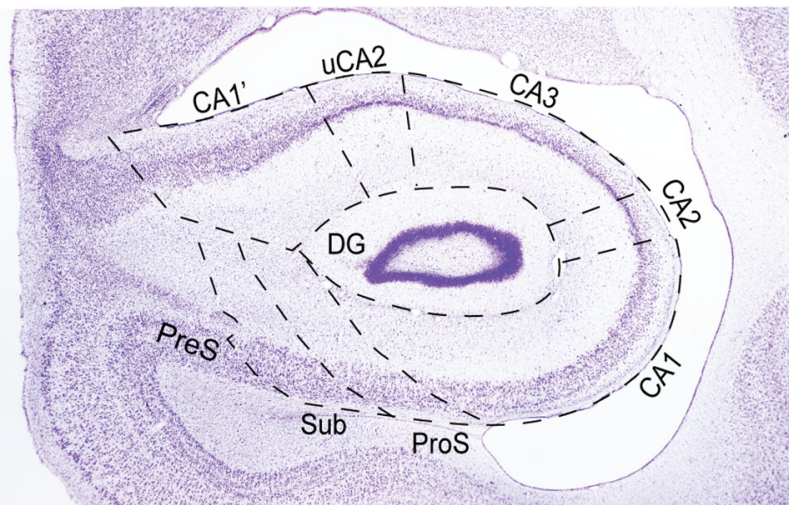

\section{$\mathbf{A}^{\prime}$}

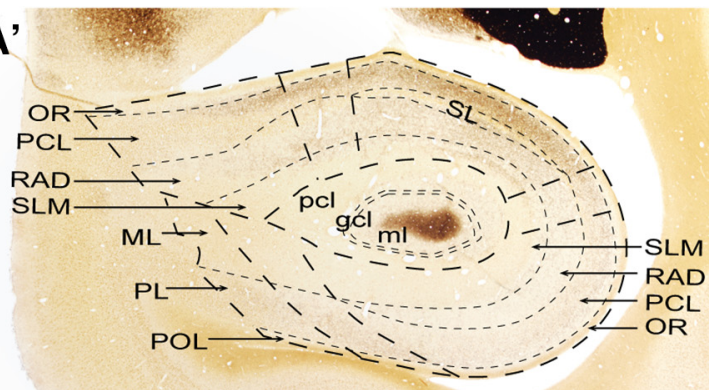

B
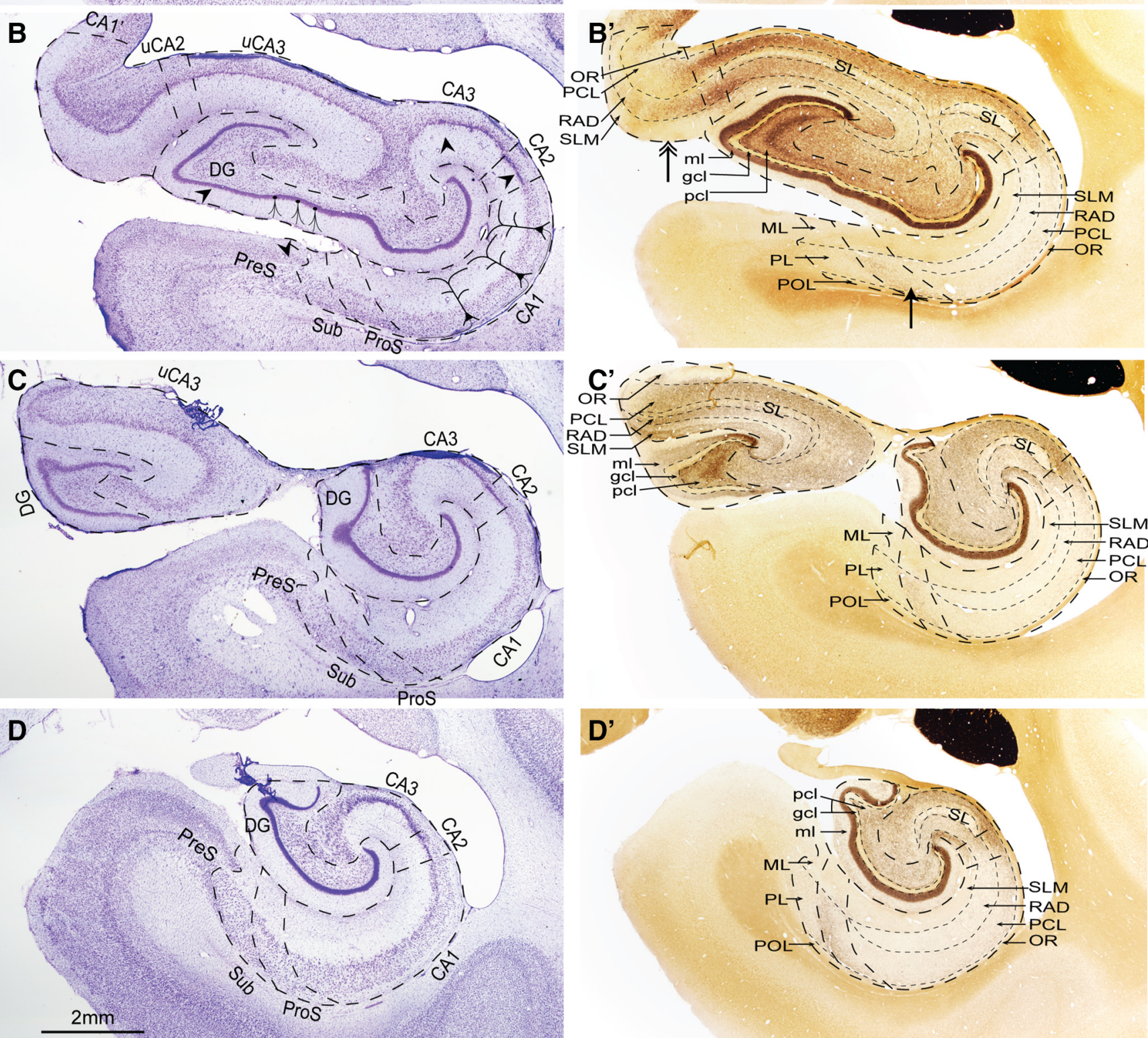

D'

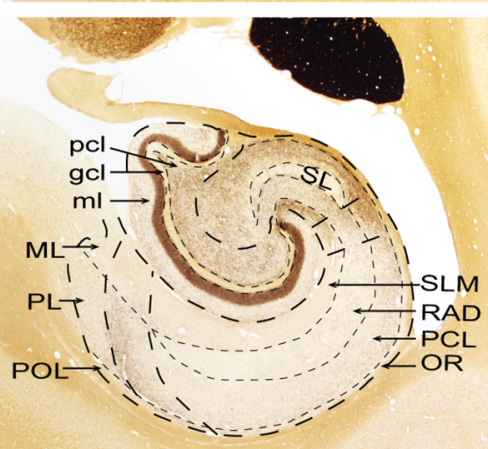

Figure 1. Regional and laminar architecture of the primate hippocampus. $A-D$, Photomicrographs of coronal sections through the hippocampus stained for Nissl show the cytoarchitecture. $A^{\prime}-D^{\prime}$, Photomicrographs of matched sections stained for $A C h E$. Representative sections are shown from anterior (top) to posterior (bottom) hippocampal levels: the genu region $\left(\boldsymbol{A}, \boldsymbol{A}^{\prime}\right)$; the uncus $\left(\boldsymbol{B}, \boldsymbol{B}^{\prime}\right)$; the most posterior uncal level $\left(\boldsymbol{C}, \boldsymbol{C}^{\prime}\right)$; and the body of the hippocampus $\left(\boldsymbol{D}, \boldsymbol{D}^{\prime}\right)$. The sections in the left panels show the borders of subregions (marked by thick dotted lines); matched sections on the right show the borders of subregions and layers (marked by thin dotted lines). In $\boldsymbol{B}^{\prime}$, the arrow points to the ProS and the double-head arrow points to the uncus. In $\boldsymbol{B}$, the arrowheads point to the distinct features of each subregion. Sketches of three granule and pyramidal cells drawn in $\boldsymbol{B}$ show the arrangement of the neuron bodies, dendrites, and fibers according to the layers. The granule cell bodies are depicted by black dots, and black lines represent dendrites. The pyramidal neuron bodies are shown as black triangles with apical tufts, oblique and basal dendrites in thick black lines, and axons in thin black lines. CA, Cornu ammonis; PreS, presubiculum. Scale bar, $2 \mathrm{~mm}$. 
neurons in the hippocampus, we used four additional monkeys (age range, 2-3 years; 4 females; cases: BJ, BF, BH, and BI; Table 1). Experiments were conducted following protocols approved by the Institutional Animal Care and Use Committees at New England Primate Research Center, Harvard Medical School, and Boston University in accordance with National Institutes of Health $(\mathrm{NIH})$ guidelines (Department of Health, Education, and Welfare Publication no. [NIH] 80-22, revised 1996, Office of Science and Health Reports, Division of Receipt and Referral/NIH, Bethesda, MD).

In all monkeys, we first conducted magnetic resonance imaging (MRI) to calculate stereotaxic coordinates for the injections sites. For MRI, animals were anesthetized with propofol and positioned in a stereotaxic apparatus (Kopf 1430M, David Kopf Instruments). About a week later, we sedated the animals with ketamine hydrochloride, followed by isoflurane to achieve a surgical level of anesthesia. We performed surgery for tracer injections under sterile conditions, while closely monitoring respiratory rate, oxygen saturation, heart rate, and temperature. We used the same stereotaxic apparatus to stabilize the head and guide the trajectories of the microsyringes ( 5 or $10 \mu$ l syringes; Hamilton). To inject the designated areas, a small area of the cortex was exposed above the injection site using the coordinates calculated before surgery. In the four cases used for pathway studies, we injected a mixture of retrograde $(3 \mathrm{kDa})$ and anterograde $(10 \mathrm{kDa})$ tracers with a final concentration of $10 \%$ : FluoroRuby (FR; tetramethylrhodamine dextran, Invitrogen; cases BL and $\mathrm{BM}$ ), Fluoro-Emerald (FE; fluorescein dextran, Invitrogen; case BN), and biotinylated dextran amine (BDA; Invitrogen; case BT); 3-5 $\mu \mathrm{l}$ of tracers were released in the amygdala (see Fig. 2). In four other cases (cases $\mathrm{BJ}, \mathrm{BF}, \mathrm{BH}$, and $\mathrm{BI}$ ), we studied the organization of inhibitory neurons in the hippocampus.

After $18 \mathrm{~d}$, the animals were sedated with ketamine, and then deeply anesthetized with sodium pentobarbital and transcardially perfused with $4 \%$ paraformaldehyde and $0.2 \%$ glutaraldehyde in $0.1 \mathrm{~m}$ PBS. The brains then were removed from the skull and preserved in ascending sucrose solution for cryoprotection ( $10-25 \%$ sucrose in $0.01 \mathrm{~m} \mathrm{PBS,} \mathrm{pH} \mathrm{7.4,} \mathrm{with}$ $0.05 \%$ sodium azide; Sigma-Aldrich), and the pia was removed. After the brain sank in the final sucrose solution, we froze the brain in isopentane solution $\left(-70^{\circ} \mathrm{C}\right.$; Thermo Fisher Scientific) and cut it on a freezing microtome [(AO Scientific Instruments) Reichert Technologies] in the coronal plane at $50 \mu \mathrm{m}$ in 10 series. The frozen brain was photographed (EOS 5D camera, Canon) after each section for reconstruction of the brain. The sections were stored until use in $-20^{\circ} \mathrm{C}$ with antifreeze solution ( $30 \%$ ethylene glycol, $30 \%$ glycerol, and $0.05 \%$ sodium azide in $0.1 \mathrm{M}$ $\mathrm{PB}, \mathrm{pH}$ 7.4).

\section{Tissue processing to visualize amygdalar terminations: light microscopy}

We processed one series of sections ( 1 in 20 sections) to view amygdalar terminations at the level of the system using LM. For the case with BDA injection, free-floating sections were rinsed with $\mathrm{PBS}(0.01 \mathrm{M}, \mathrm{pH} 7.4)$, incubated at $80^{\circ} \mathrm{C}$ in sodium citrate solution $(10 \mathrm{~mm}, \mathrm{pH}$ 8.5; SigmaAldrich) for $30 \mathrm{~min}$ to retrieve antigen. Tissue sections then went through incubation at $4^{\circ} \mathrm{C}$ with glycine ( $0.05 \mathrm{~m}$ in PBS; Sigma-Aldrich) for $1 \mathrm{~h}$, hydrogen peroxide ( $0.3 \%$ in PBS; Sigma-Aldrich) for $30 \mathrm{~min}$, preblocking solution for $1 \mathrm{~h}$ [ $10 \%$ normal goat serum (Vector Laboratories), $10 \%$ bovine serum albumin (BSA; Sigma-Aldrich), 0.2\% BSA-c (Aurion), and $0.2 \%$ Triton X-100 (Sigma-Aldrich) in $0.01 \mathrm{M} \mathrm{PBS].} \mathrm{After}$ the preblock, tissue sections were incubated in avidin-biotin horseradish peroxidase (AB-HRP; catalog \#PK-6100, Vector Laboratories; RRID: AB_2336827) at a 1:100 dilution in PBS for $1 \mathrm{~h}$, and then processed with diaminobenzidine (DAB) for 2-3 min (catalog \#SK-4100, Vector Laboratories; RRID:AB_2336382).

For cases with FE and FR injections, tissue sections went through antigen retrieval, glycine incubation, and hydrogen peroxide incubation, as cited above. We then incubated tissue sections with $\mathrm{AB}$ blocking solution (catalog \#SP-2001, Vector Laboratories; RRID:AB_2336231) and preblocking solution. After preblock, we incubated tissue sections at $4^{\circ} \mathrm{C}$ for $2 \mathrm{~d}$ with primary antibodies to tracers [rabbit anti-FE (catalog \#A889, Invitrogen; RRID:AB_221561), rabbit anti-FR (catalog \#A6397, Invitrogen; RRID:AB_1502299)] at 1:800 in preblocking solution. During incu- bation, we microwaved (BioWave, Ted Pella) the tissue sections twice a day ( $3 \mathrm{~min}$ on, $2 \mathrm{~min}$ off, $3 \mathrm{~min}$ on, at $150 \mathrm{~W}$ ) to enhance antibody penetration. After PBS rinsing, we incubated tissue sections overnight in secondary antibody solution (biotinylated goat anti-rabbit IgG; catalog \#BA-1000, Vector Laboratories; RRID:AB_2313606) at 1:200 in preblocking solution at $4^{\circ} \mathrm{C}$ with two microwave sessions, followed by $\mathrm{AB}-$ $\mathrm{HRP}$ incubation and DAB, as described above. After every step, we rinsed tissue sections with PBS $(3 \times 10 \mathrm{~min}, 0.01 \mathrm{M}, \mathrm{pH} 7.4)$.

\section{Tissue processing to study the architecture of the hippocampus}

To study the cytoarchitecture, we stained for Nissl every other section labeled for the pathway. We rinsed sections with $0.1 \mathrm{M} \mathrm{PB}, \mathrm{pH} 7.4$, and mounted them on gelatin-coated glass slides. After $\geq 10 \mathrm{~d}$ of drying, we stained every other section for Nissl and coverslipped the rest directly with Entellan Mounting Medium (Electron Microscopy Sciences). For Nissl staining, we placed sections in a 1:1 chloroform-ethanol solution for $3 \mathrm{~h}$; rehydrated them in descending ethanol solutions (100\%, 95\%, $70 \%)$ and distilled water $\left(\mathrm{dH}_{2} \mathrm{O}\right)$; stained them with $0.05 \%$ thionin for 1-2 min, and then rinsed with $\mathrm{dH}_{2} \mathrm{O}$; dehydrated them with a series of ascending ethanol solutions $(70 \%, 95 \%, 100 \%)$; cleared them in xylene; and coverslipped them with Entellan Mounting Medium.

To study the chemoarchitecture of the hippocampus, we stained sections for AChE through the hippocampus adjacent to those labeled for $\mathrm{DAB}$ to view pathways. A detailed protocol was described previously (Zikopoulos et al., 2016). Tissue sections were briefly rinsed with $\mathrm{dH}_{2} \mathrm{O}$ (6X), incubated overnight at $4^{\circ} \mathrm{C}$ in the AChE solution [0.2 mM ethopropazine hydrochloride (Sigma-Aldrich), $4 \mathrm{~mm}$ acetylthiocholine iodide (Sigma-Aldrich), 10 mm glycine (Thermo Fisher Scientific), 2 mм cupric sulfate pentahydrate (Thermo Fisher Scientific), and $50 \mathrm{~mm}$ sodium acetate (Sigma-Aldrich) in $\mathrm{dH}_{2} \mathrm{O}$ (titrated to $\mathrm{pH} 5.0$ with acetic acid)]. Tissue sections then were rinsed with $\mathrm{dH}_{2} \mathrm{O}(6 \times)$, incubated for $2-5 \mathrm{~min}$ at $25^{\circ} \mathrm{C}$ in $8 \mathrm{~mm}$ sodium sulfide solution [sodium sulfide nonahydrate (Sigma-Aldrich), titrated to $\mathrm{pH} 7.8$ with $3 \mathrm{~N}$ hydrochloric acid], rinsed with $\mathrm{dH}_{2} \mathrm{O}(6 \times)$, followed by incubation for $5-30 \mathrm{~min}$ at $25^{\circ} \mathrm{C}$ in $1 \%$ silver nitrate solution (Thermo Fisher Scientific). After final rinses in PBS (0.01 M, pH 7.4), we mounted tissue sections on gelatin-coated glass slides and coverslipped them with Entellan Mounting Medium.

\section{Tissue processing to study calretinin and parvalbumin} neurons: immunofluorescence

To determine whether CR or PV are reliable markers for inhibitory neurons in primate hippocampus, we double labeled tissue sections with GABA and calcium-binding proteins. Sections of the hippocampus went through antigen retrieval, glycine incubation, and preblocking, as described above. We incubated tissue sections for $2 \mathrm{~d}$ with the respective antibodies [mouse anti-CR (catalog \#6B3, Swant; RRID:AB_10000320) or mouse-anti-PV (catalog \#235, Swant; RRID:AB_10000343) at 1:2000 and rabbit anti-GABA (catalog \#20095, Immunostar; RRID:AB_572233) at 1:1000 in preblocking solution]. For studies to determine calciumbinding protein distribution, we incubated tissue sections for $2 \mathrm{~d}$ with PV or CR [mouse anti-CR and rabbit anti-PV (catalog \#PV27, Swant; RRID: $\left.A B \_2631173\right)$ at 1:2000 in preblocking solution], with microwave sessions twice per day. We then incubated tissue sections overnight in secondary antibodies conjugated with fluorescent label [Alexa Fluor 568 goat anti-rabbit IgG (catalog \#A11011, Invitrogen; RRID:AB_143157) or goat anti-mouse IgG (catalog \#A11019, Invitrogen; RRID:AB_143162) and Alexa Fluor 488 goat anti-mouse IgG (catalog \#A11001, Invitrogen; RRID:AB_2556548) or goat anti-rabbit IgG (catalog \#A11008, Invitrogen; RRID:AB_143165)] at 1:100 in preblocking solutions with two microwave sessions. The fluorescent colors were chosen to minimize background and photo bleaching. We then rinsed tissue sections with $\mathrm{PB}$ (0.1 M, pH 7.4), mounted them on gelatin-coated glass slides, dried them overnight, and coverslipped them with Prolong Gold Antifade Mounting Medium (catalog \#36930, Invitrogen). For control experiments, we incubated tissue sections only in either the primary or secondary antibody and found no evidence of immunolabeling. 
Tissue processing to study appositions with inhibitory neurons: immunofluorescence

To visualize two antigens simultaneously, we used double-labeling immunohistochemistry. Sections of the anterior hippocampus went through antigen retrieval, glycine incubation, preblocking, primary antibody incubation for $2 \mathrm{~d}$, and secondary antibody incubation overnight, as described above. The only difference was the use of primary antibodies for apposition analysis (rabbit anti-FE or rabbit anti-FR at 1:800; and mouse anti-CR or mouse anti-PV at 1:2000 in the preblocking solution).

Tissue processing for electron microscopy

Our findings of amygdalar terminations in the entire hippocampus helped to guide the selection of sections with dense terminations to be processed for the analysis of presynaptic and postsynaptic sites at much higher resolution in EM. To visualize amygdalar terminations and $\mathrm{CR}^{+}$ or $\mathrm{PV}^{+}$neurons in the hippocampus with EM, we used embedding immunohistochemistry, which labeled boutons with tracers using DAB (uniform black) and calcium-binding proteins with scattered gold particles (black, round dots). The immunohistochemistry procedures were the same as described above, with reduced Triton X-100 (0.025\%, Roche Applied Science) to help preserve the fine structure in the preblocking solutions for the primary and secondary antibody incubation, with $0.1 \%$ cold water fish gelatin (Aurion) added to preblocking solutions for secondary antibody incubation. We labeled PV or CR with gold-conjugated secondary antibodies [1:100; UltraSmall ImmunoGold $\mathrm{F}(\mathrm{ab})$ fragment of goat anti-mouse IgG; catalog \#800.266, Aurion; (RRID:AB_2315632)]. After incubation with secondary antibodies, tissue sections went through low-glutaraldehyde fixation [3\% glutaraldehyde and $1 \%$ paraformaldehyde in $0.1 \mathrm{M} \mathrm{PB}$ with a microwave session $\left(2 \mathrm{~min}\right.$ at $\left.\left.150 \mathrm{~W}, 4^{\circ} \mathrm{C}\right)\right]$, glycine wash ( $50 \mathrm{~mm}$ in $0.1 \mathrm{M} \mathrm{PB}, 5 \mathrm{~min}$ ), and rinsed twice in $\mathrm{PB}(0.1 \mathrm{M}, 10 \mathrm{~min})$ and twice in enhancement conditioning solution (1:10, $10 \mathrm{~min}$, Aurion). To enhance the appearance of gold particles, we incubated sections in the silver enhancement solution for $90 \mathrm{~min}$ (R-Gent SE-EM, Aurion). The reaction was stopped by $0.1 \mathrm{M} \mathrm{PB}$ rinses $(3 \times 10 \mathrm{~min}$ ) followed by $\mathrm{AB}-$ HRP incubation and DAB, as described above.

After processing with $\mathrm{DAB}$, we quickly placed the wet tissue sections on glass slides and photographed them with a CCD camera mounted on a microscope (model BX51, Olympus). We used the images to identify the densest regions with DAB-labeled axons and boutons in the SLM layer of CA1 and CA3 for further processing and detailed EM study.

We then postfixed tissue sections in $6 \%$ glutaraldehyde and $2 \%$ paraformaldehyde in $\mathrm{PB}$ in a microwave oven $\left(150 \mathrm{~W}\right.$ at $\left.15^{\circ} \mathrm{C}\right)$ until the sample temperature reached $30-35^{\circ} \mathrm{C}$, and incubated them for an additional $30 \mathrm{~min}$ at $25^{\circ} \mathrm{C}$ followed with $0.1 \mathrm{M} \mathrm{PB}$ rinses for $30 \mathrm{~min}$ (Jensen and Harris, 1989). For control experiments, we incubated tissue sections only in either the primary antibody or secondary antibody and found no evidence of immunolabeling.

To introduce heavy metals into the tissue to view in the EM, we used the following two processes: routine EM (for ultrathin section and 2D analysis), and block-face imaging EM (for block-surface imaging and 3D analysis). The routine EM methods for ultrathin sectioning have been described previously (Zikopoulos et al., 2016; García-Cabezas and Barbas, 2017). For EM block-face imaging, we washed tissue sections with $0.1 \%$ tannic acid (Sigma-Aldrich) in $0.1 \mathrm{~m}$ sodium cacodylate buffer (Sigma-Aldrich) for $30 \mathrm{~min}$ at $25^{\circ} \mathrm{C}$, with an additional rinse with $0.1 \mathrm{M}$ sodium cacodylate buffer $(3 \times 5 \mathrm{~min})$. We then postfixed tissue sections for $20 \mathrm{~min}$ in 2\% osmium tetroxide (Electron Microscopy Sciences) with $1.5 \%$ potassium ferrocyanide (Electron Microscopy Sciences) in $\mathrm{d}_{2} \mathrm{O}$ with a microwave session $\left(100 \mathrm{~W}\right.$ at $4^{\circ} \mathrm{C} ; 6$ min under vacuum) and poststained them for an additional $30 \mathrm{~min}$. After three $\mathrm{dH}_{2} \mathrm{O}$ rinses, we incubated tissue sections for $30 \mathrm{~min}$ in $1 \%$ thiocarbohydrazide in $\mathrm{dH}_{2} \mathrm{O}$ (Sigma-Aldrich) and rinsed them with $\mathrm{dH}_{2} \mathrm{O}(3 \times 5 \mathrm{~min})$. We then incubated tissue sections with a second osmium solution ( $2 \%$ osmium tetroxide in water) with a microwave session $\left(100 \mathrm{~W}\right.$ at $4^{\circ} \mathrm{C} ; 6$ min under vacuum) and poststained them for $20 \mathrm{~min}$, rinsed them in $\mathrm{dH}_{2} \mathrm{O}(3 \times 5$ min), and stained overnight at $4^{\circ} \mathrm{C}$ with $1 \%$ uranyl acetate in $\mathrm{dH}_{2} \mathrm{O}$ (Electron Microscopy Sciences). On the second day, we rinsed tissue sections with $\mathrm{dH}_{2} \mathrm{O}(3 \times 5 \mathrm{~min})$, incubated them in lead aspartate staining solution [0.066 g lead nitrate (Electron Microscopy Sciences) dis- solved in $10 \mathrm{ml}$ of $0.4 \%$ L-aspartic acid in $\mathrm{dH}_{2} \mathrm{O}$ and titrated to $\mathrm{pH} 5.5$ with $20 \%$ potassium hydroxide solution (Sigma-Aldrich)] for $30 \mathrm{~min}$ at $60^{\circ} \mathrm{C}$, and dehydrated sections in ascending graded ethanols $(50 \%, 75 \%$, $85 \%, 95 \%, 100 \% ; 3 \times 5$ min each). Tissue sections were then infiltrated with propylene oxide ( $2 \times 10 \mathrm{~min}$; Electron Microscopy Sciences), a 1:1 mixture of LX112 resin (LX112 Embedding Kits, Ladd Research Industries ) and propylene oxide ( $1 \mathrm{~h})$, and a 2:1 mixture of LX112 resin and propylene oxide at $25^{\circ} \mathrm{C}$ (overnight). The following day, the tissue sections were infiltrated with pure LX112 resin for $4 \mathrm{~h}$ under vacuum, flat embedded in LX112 resin in Aclar (Ted Pella), and cured for $\geq 48 \mathrm{~h}$ at $60^{\circ} \mathrm{C}$.

With the aid of a stereomicroscope, we cut small cubes of Aclarembedded tissue that contained the SLM layer of CA1 or CA3. To locate the region of interest with the densest pathway labeling on Aclarembedded brain tissue, we used fiduciary landmarks (e.g., blood vessels) from the captured images of the wet tissue after the DAB-processing stage (described above). We then placed the excised small cubes on top of premade LX112 resin blocks with fresh LX112 resin and cured them for $\geq 48 \mathrm{~h}$ at $60^{\circ} \mathrm{C}$. We then mounted LX112 resin blocks with sections on an ultramicrotome (Ultracut UCT, Leica Microsystems), cut them into 50 $\mathrm{nm}$ ultrathin sections, and collected them in order on pioloform-coated copper slot grids to form series of $20-50$ sections. To visualize the ultrastructure, we used an $80 \mathrm{kV}$ transmission electron microscope (100CX, JEOL) at 1000-33,000×. We viewed sections in EM and captured DABlabeled amygdalar boutons with synapses for 2D EM analyses using a digital camera (DigitalMicrograph, GATAN).

For block-face imaging, we sectioned small cubes of Aclar-embedded tissue that contained the SLM of CA1 or CA3 and glued them onto aluminum pins with conductive epoxy glue (catalog \#CW2400, Chemtronics). The extra resin and glue were cut using an ultramicrotome to expose the surface of the tissue. We then coated the edge of the specimen with silver paint (catalog \#16035, Ted Pella) to reduce charging. We mounted the pins with sections in the 3View 2XP System (GATAN) coupled to a $1.5 \mathrm{KV}$ scanning electron microscope (GeminiSEM 300, Zeiss). The surface of the section was captured using a backscattered detector. A built-in ultramicrotome in the 3View 2XP System cut the surface of the sections with $50 \mathrm{~nm}$ thickness, and $20 \times 20$ to $25 \times$ $25 \mu \mathrm{m}$ fields were captured after each cut at a resolution of $6-7 \mathrm{~nm}$ to form series of images. DAB-labeled amygdalar boutons in the image series were collected for 3D EM studies.

\section{Data analysis}

Axon tracing mappings. In two cases (cases BM and BN), we used representative coronal sections from one series (representing 1 in 20 sections) through the anterior and posterior hippocampus to exhaustively trace axon terminals. We divided the series into two halves, used a representative middle section from each half for the anterior and posterior hippocampus, and exhaustively mapped the amygdalar terminations. In an additional case (BT), we used representative sections at short intervals across the entire longitudinal axis of the hippocampus. To show the levels of each plotted section, we reconstructed the brain and hippocampus using the images of all brain sections captured at the time of cutting the brain (as described above).

We placed boundaries of hippocampal subregions and laminae using a microscope (model BX51 or BX60, Olympus America) and software [Neurolucida (RRID:SCR_001775) or Stereo Investigator version 10 (RRID:SCR_002526), mbf Bioscience], using matched sections stained for Nissl and AChE (Fig. 1).

Unbiased stereology. This method (West, 2012) allowed us to quantify the pattern of amygdalar terminations in hippocampal subregions throughout the hippocampus in all cases with tracer injections into the amygdala. We conducted stereologic analysis using a semiautomated system (StereoInvestigator version 10 and a model BX60 camera, Olympus America) in one series of sections (representing 1 in 20 sections; $\sim 13$ sections included the hippocampus) in each case. Using the architectonic analysis as a guide, we first subdivided the hippocampal subregions and their layers in each coronal section. To randomly sample each hippocampal subregion and layer using an unbiased stereologic method we set the size of the counting frame $(50 \times 50 \mu \mathrm{m})$ and the disector height $(2-5 \mu \mathrm{m})$. 
The grid spacing varied depending on bouton density for each hippocampal subregion and layer $(50 \times 50 \mu \mathrm{m}, 100 \times 100 \mu \mathrm{m}, 500 \times 500 \mu \mathrm{m})$, chosen so that the sampling reached a Gundersen coefficient of error $(m=1)$ of $<0.1$. A Gundersen error of $\leq 10 \%$ indicates sufficient sampling (West, 2012). We conducted stereologic analysis to estimate the number of boutons and volume in each hippocampal subregion and layer. In each case, we divided the mapped series of sections into three sectors, for the anterior, middle, and posterior hippocampus, and estimated labeled boutons and volume in each third.

Bouton size analysis and features of amygdalar pathways (confocal microscopy and EM). We first measured the diameter of boutons using laser-scanning confocal microscopy. Amygdalar boutons were labeled with the corresponding fluorescent label, as described above, and we used double labeling to also view their postsynaptic sites on inhibitory neurons. We acquired stacks of optical sections $(0.31$ or $0.33 \mu \mathrm{m})$ in the SLM layer of CA1 and CA3 using confocal microscopy (model LSM $880 \mathrm{mi}-$ croscope, Zeiss; or Andor). To reduce blurring, we used deconvolution for each stack (AutoDeblur X software, Media Cybernetics; RRID: SCR_002465). We then imported the stack of images into Reconstruct (SynapseWeb; RRID:SCR_002716; Fiala, 2005) and circled fluorescentlabeled amygdalar boutons manually for maximum diameter. We measured $>1000$ boutons for cases with dense label (cases BL, BM, and BT) and $>500$ boutons for a case with sparse label (case BN) in the SLM layer of CA1 and CA3. We plotted boutons for each case to show the frequency distribution.

We also measured amygdalar bouton diameter using EM for 2D analysis (100CX, JEOL) and 3D analysis (GeminiSEM 300 coupled with 3 View $2 X P$ system). For 2D analysis, we measured the diameter with five or more sequential sections containing amygdalar boutons using Reconstruct, as described previously (Medalla and Barbas, 2009; Timbie and Barbas, 2014). We conducted 3D analysis for bouton diameter and volume in series of sections. Only boutons with complete profiles were counted. We measured the PSD surface area using 3D EM analysis, and calculated the proportion of perforated PSDs and mitochondria with both 2D and 3D EM analyses. In long series of EM sections (number, 37-296; case BL), we reconstructed the amygdalar terminations and their postsynaptic targets to study distinct features of amygdalar pathways.

In 2D EM series, we measured the diameter of all boutons that formed synapses in the same plane with the amygdalar boutons (cases BL, BM, and $\mathrm{BN}$ ). In 3D EM, we used series with a high number of labeled amygdalar boutons to measure the diameter of boutons in the neuropil (case BL). We examined 1 in every 50 sections, measured the diameter of boutons that formed synapses, and pooled boutons in the neuropil from 2D and 3D EM series for each case.

Calcium-binding protein expressing neurons in the hippocampus. We used double-labeling immunohistochemistry staining in sections from the anterior hippocampus to label for GABA and PV or CR, as described above (cases $\mathrm{BJ}, \mathrm{BF}, \mathrm{BH}$, and $\mathrm{BI}$ ). We plotted neurons that expressed GABA, PV, or CR in the hippocampus exhaustively using Neurolucida or Stereo Investigator 10 software, as described above.

Analyses of the postsynaptic targets of amygdalar terminations (confocal microscopy and EM). We counted exhaustively amygdalar boutons in stacks acquired with confocal microscopy. If a bouton contacted a labeled $\mathrm{PV}^{+}$or $\mathrm{CR}^{+}$element, including an area of colocalization at the point of contact, it was counted as an apposition. We examined all amygdalar boutons captured with 2D and 3D EM methods for features of their postsynaptic targets, including dendrites, spines, synapses at more than one site, and synapses on $\mathrm{PV}^{+}$or $\mathrm{CR}^{+}$elements.

\section{Statistics}

We compared the proportion of amygdalar boutons in each area across cases (cases BL, BM, BN, and BT) using ANOVA with Bonferroni's post hoc test. We used two-tailed $t$ tests to compare the proportion of boutons in anterior versus posterior hippocampus. We compared bouton diameters, volumes, PSD areas, and morphologic features between SLM layers of CA1 and CA3 using a two-tailed $t$ test, as well as bouton diameter between amygdalar and neuropil boutons. We used linear regression for PSD surface area and bouton volume or diameter. We compared the proportion of amygdalar boutons apposed on $\mathrm{PV}^{+}$or $\mathrm{CR}^{+}$neurons between SLM layer of CA1 and CA3 using $\chi^{2}$ test. We compared the proportion of amygdalar boutons that formed synapses on different postsynaptic targets between the SLM layers of CA1 and CA3 using a two-tailed $t$ test in EM analyses. We used SPSS software (IBM; RRID: SCR_002865) for all statistical analyses.

\section{Results}

\section{Architecture of the hippocampus}

The hippocampus can be divided into different subregions and layers, which have distinct roles in memory processes (for review, see Amaral and Lavenex, 2006). Details of the architecture of the macaque monkey hippocampus can be found in previous studies (Bakst and Amaral, 1984; Rosene and Van Hoesen, 1987). A brief account is included here, with the needed detail to help increase precision in the maps of amygdalar terminations. The different subregions of the macaque monkey hippocampus can be delineated using Nissl staining to show the cytoarchitecture and AChE to show the chemoarchitecture (Bakst and Amaral, 1984; Rosene and Van Hoesen, 1987; Barbas and Blatt, 1995). As shown in Figure 1, the dentate gyrus (DG) is surrounded by the CA fields, prosubiculum (ProS), and subiculum (Sub), which are seen at almost all levels of the anterior-posterior hippocampus. We divided the CA fields into CA1, CA2, and CA3, as adapted from previous studies (Amaral and Insausti, 1990; Barbas and Blatt, 1995). We did not separate CA4 from the hilus of the DG, since amygdalar termination patterns were similar in CA4 and the DG, and sparser than in CA3. We call the above "subregions."

The hippocampus is also divided into layers, which contain different compartments of the pyramidal neurons (Amaral and Lavenex, 2006). As shown in Figure $1, B$ and $B^{\prime}$, in a direction away from the hippocampal fissure, the CA fields contain these following layers: SLM, which includes the apical tufts of the pyramidal neurons; stratum radiatum (RAD), which includes the apical trunk and oblique dendrites of the pyramidal neurons; stratum pyramidale (PCL), populated by the pyramidal neuron bodies; stratum oriens (OR), which includes the basal dendrites of the pyramidal neurons; and the alveus, which includes axon fibers. In this study, we combined the alveus with the OR, as the two strata are relatively thin and contain very sparse amygdalar terminations. The CA3 has an additional layer, the stratum lucidum (SL), which receives projections from the DG (Fig. 1).

The DG is subdivided into three layers, including a molecular layer $(\mathrm{ml})$, a granule cell layer $(\mathrm{gcl})$, and a polymorphic cell layer (pcl). The ProS and Sub have a molecular layer (ML), a pyramidal cell layer (PL), and a polymorphic cell layer (POL; Fig. 1B'). Each subregion has unique features: the DG is distinct with its dense gcl; the CA3 stands out by the SL; the CA2 has the thinnest PCL; the CA1 lies between CA2 and ProS. The ProS is identifiable by the loss of the RAD. The neighboring Sub is an allocortical structure that differs from the adjacent periallocortical presubiculum, which is distinguished by an added upper cellular layer (Fig. 1B). In the most anterior levels, the macaque monkey hippocampus bends medially and then caudally to form the uncus (Rosene and Van Hoesen, 1987), which includes CA1', and uncal CA2 (uCA2) and uncal CA3 (uCA3), as shown in Figure $1 A-C$. The pattern of AChE distribution helped to identify the hippocampal layers in conjunction with Nissl staining, including the relative paucity of $\mathrm{AChE}$ in SL and its moderate distribution in ProS (Fig. $\left.1 A^{\prime}-D^{\prime}\right)$.

\section{Injection sites}

Figure 2 shows the injection sites in the right amygdala (four cases). The neural traces included BDAs (case BT), FR (cases BM and $\mathrm{BL}$ ), and $\mathrm{FE}$ (case $\mathrm{BN}$ ). All injections were in the right hemi- 
A

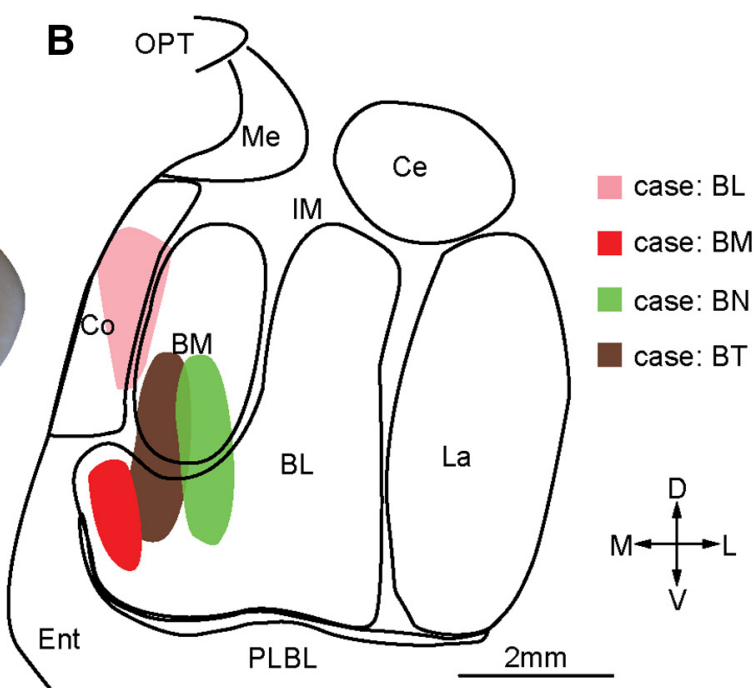

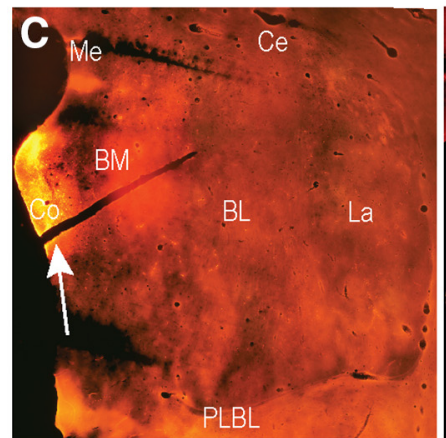

Case: BL

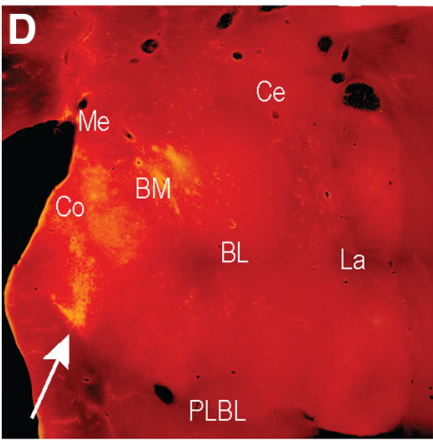

Case: BM

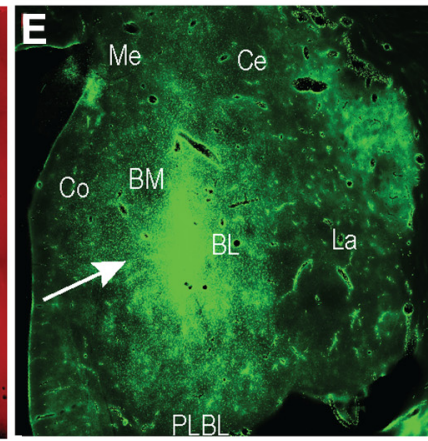

Case: BN

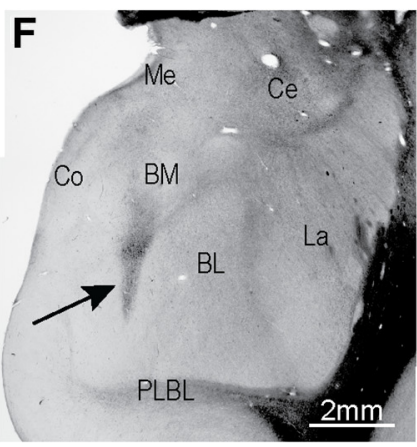

Case: BT

Figure 2. Experimental design and injection sites in the amygdala. $\boldsymbol{A}$, Scheme of the anterograde tracer trajectory: from neurons (black cones) along the axons to the hippocampus; the arrow shows the direction. Photograph of the medial surface of a monkey brain shows the location of the amygdala (rostral) and hippocampus (caudal) in salmon color. Scale bar, $1 \mathrm{~cm}$. $\boldsymbol{B}, \mathbf{S c h e m a t i c ~ o f ~}$ coronal section through the amygdala shows the injection sites. $\boldsymbol{C}-\boldsymbol{E}$, Fluorescent photomicrographs show the injection sites in the amygdala. $\boldsymbol{F}$, Fresh tissue shows the BDA injection in the amygdala under dark-field illumination. The arrows in $\boldsymbol{C} \boldsymbol{F}$ indicate the injection sites. Scale bars: $\boldsymbol{B}-\boldsymbol{F}, 2 \mathrm{~mm}$. D, Dorsal; V, ventral; $\mathbf{M}$, medial; $\mathbf{L}$, lateral; $\mathbf{C e}$, central nucleus; Ent, entorhinal cortex; IM, intercalated masses; La, lateral nucleus; Me, medial nucleus; OPT, optic tract; PLBL, paralaminar BL.

sphere. The injection sites were in the medial third of the amygdala, and within the Co, basomedial nucleus [BM (also known as accessory basal)], and the basolateral nucleus (BL), which have robust connections with the macaque monkey hippocampus (Saunders et al., 1988). In one case, the injection site included the ventral part of the Co and the most medial part of the BM (Fig. 2C, case BL). Another injection site of FR was located in the parvicellular BL and impinged on the ventral part of the Co and BM (Fig. 2D, case BM). In two other cases, the injection sites were also in $\mathrm{BM}$ and $\mathrm{BL}$, somewhat more lateral than in the previous two cases (Fig. 2E, F, cases $\mathrm{BN}$ and $\mathrm{BT}$ ).

\section{Distribution of amygdalar terminations in hippocampus}

We mapped amygdalar terminations exhaustively through short intervals along the entire hippocampus in one case (Fig. 3A-E, case BT). The levels of the mapped sections are depicted on the reconstructed brain, which was rendered transparent to show in precise coordinates the deeply situated reconstructed hippocampus in $3 \mathrm{D}$ (Fig. $3 K$, case $\mathrm{BT}$ ). We also mapped exhaustively amygdalar axons in representative anterior and posterior sections of the hippocampus in two other cases (Fig. $3 G-J$, cases BM and $\mathrm{BN})$. The pattern of amygdalar terminations in these cases and in case BT was similar despite small differences among injection sites (Fig. 3F).
Terminations were densest in the anterior hippocampus, and were found mostly in the SLM layer and, to a lesser extent, in the RAD, PCL, and OR layers of the CA fields. Amygdalar terminations were also found in the ProS and Sub, where they were distributed in all layers. Very few axon terminations were found in the DG in the anterior hippocampus; they were seen only near the hippocampal fissure between the uncus and the DG, and were restricted to the $\mathrm{ml}$ (Fig. $3 A, B, G, I$ ). Posteriorly, amygdalar axon terminations were concentrated in the RAD and PCL layers at the juncture of CA1 and the ProS and in the SLM layer of CA3. Very sparse axon terminations were found in the other CA fields and the subicular complex. Light to moderate amygdalar terminations were present in the DG in the most posterior hippocampus (Fig. 3E). These findings are largely consistent with the qualitative results of the study by Saunders et al. (1988), who found that the cortical nuclei and the BM (or accessory basal) innervate the molecular layer of the ammonic fields and, more sparsely, the molecular and pyramidal cell layers of the prosubiculum (Saunders et al., 1988).

After the survey of the regional and laminar pattern of labeling, we conducted stereological analysis to determine the relative proportion of boutons from the amygdala in different hippocampal subregions, layers and sectors, with the latter referring to the anteroposterior hippocampal extent. In the entire longitudinal 
A

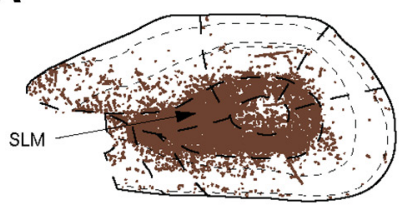

B

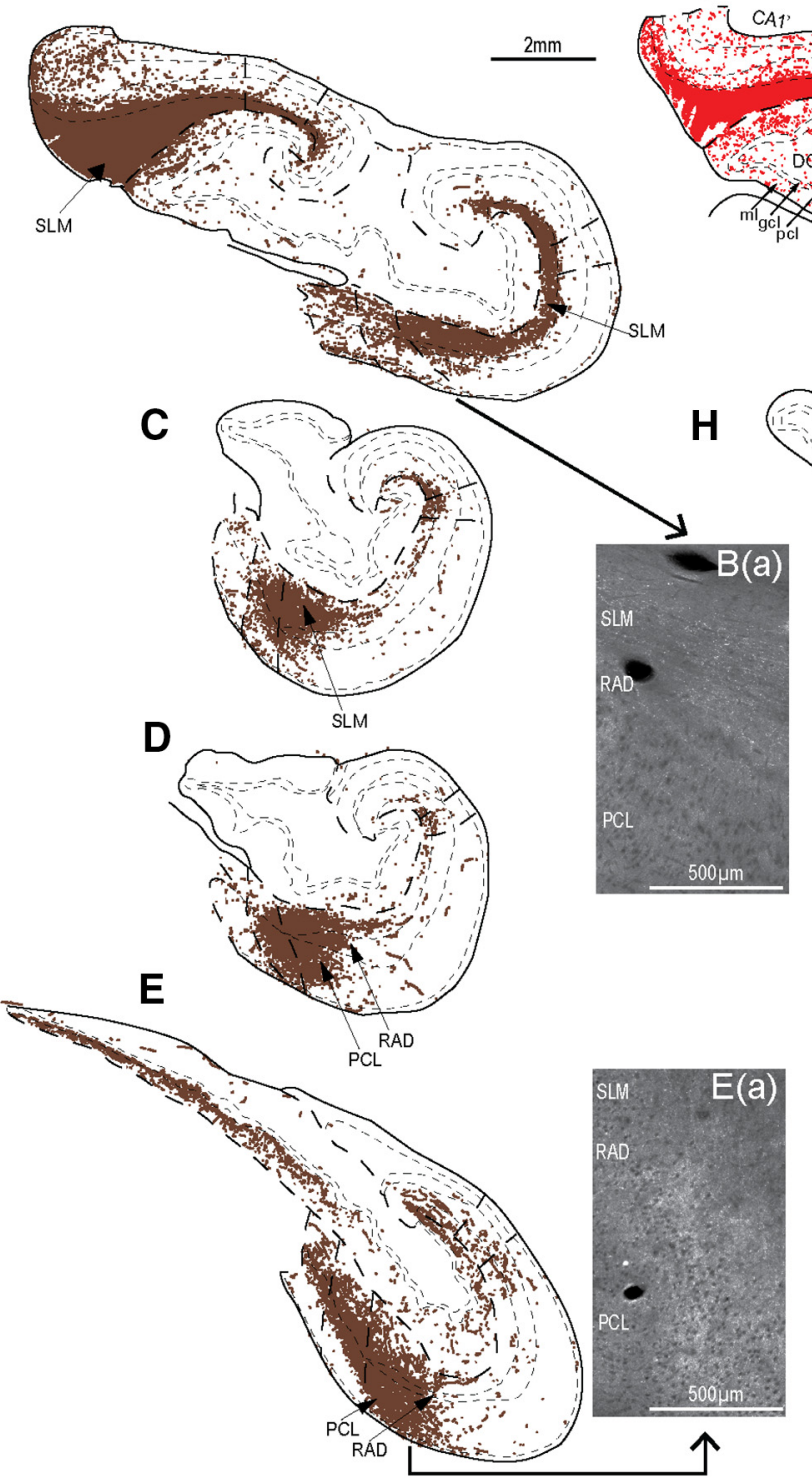

\section{G}

$\mathbf{F}$

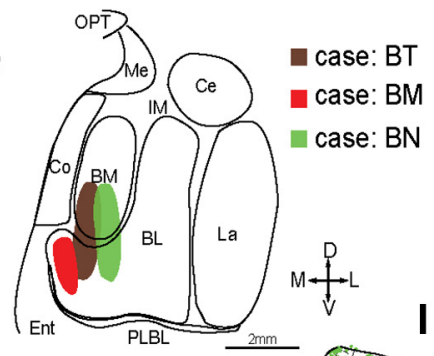

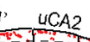

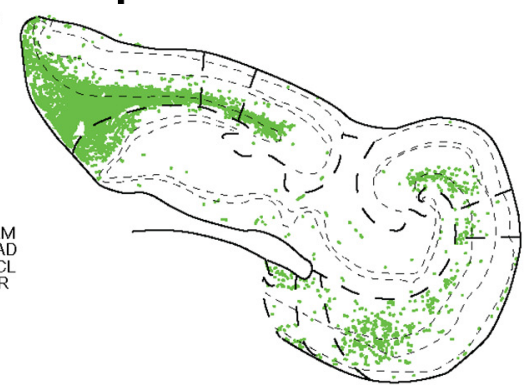

J
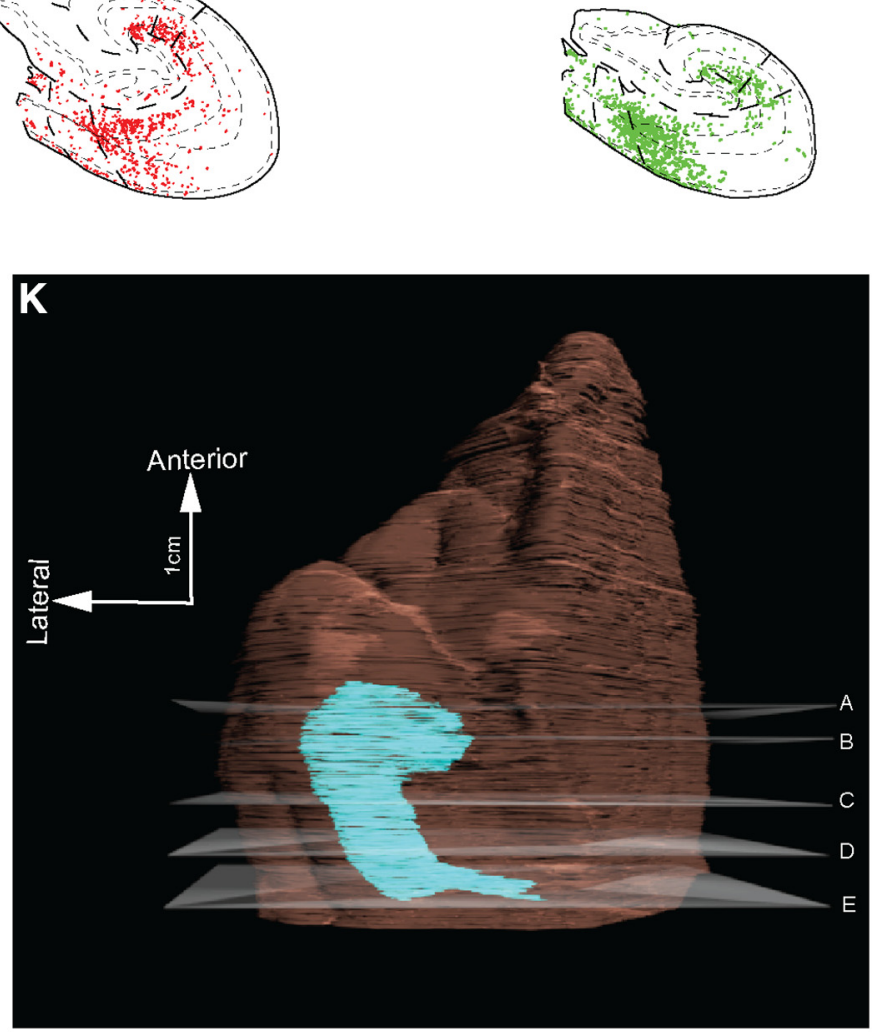

Figure 3. Amygdalar axon terminations in hippocampus. $\boldsymbol{A}-\boldsymbol{E}$, Diagrams show distribution of labeled amygdalar axon termination in coronal sections from anterior to posterior hippocampal levels ( $\boldsymbol{A}-\boldsymbol{E}$, case BT). $\boldsymbol{B}(\boldsymbol{a}), \boldsymbol{E}(\boldsymbol{a})$, Photomicrographs show amygdalar axons (white) in CA1 under dark-field illumination from an anterior level $(\boldsymbol{B})$ and a posterior level $(\boldsymbol{E})$. $\boldsymbol{F}$, Schematic of coronal section through the amygdala shows the injection sites (cases BT, BM, and BN). $\mathbf{G}-\mathbf{J}$, Diagrams of two representative coronal sections show labeled amygdalar axons in anterior $(\mathbf{G}, \mathbf{I}$ ) and posterior $(\boldsymbol{H}, \boldsymbol{J})$ hippocampal levels (case BM, $\mathbf{G}-\boldsymbol{H}$; case BN, $\boldsymbol{I}-\boldsymbol{J})$. $\boldsymbol{K}, 3 \mathrm{D}$ reconstruction of the rhesus monkey brain (case BT), which was rendered transparent to show the reconstructed hippocampus inside (blue). The horizontal gray planes through the brain show the levels of each plotted section as follows: plane A (section A); plane B (sections B, G, and I); plane C (section D); plane D (sections D, H, and J); plane $\mathrm{E}$ (section E). Scale bars: $\boldsymbol{A}-\boldsymbol{J}, 2 \mathrm{~mm} ; \boldsymbol{B}(\boldsymbol{a}), \boldsymbol{E}(\boldsymbol{a}), 500 \mu \mathrm{m} ; \boldsymbol{K}, 1 \mathrm{~cm}$ (entire arrow).

axis of the hippocampus, the proportion of amygdalar boutons was highest in CA1', CA1 and CA3 (CA1': $30.8 \pm 6 \%$; CA1: $28.6 \pm 3.6 \%$; CA3: $16 \pm 2 \%$; four cases). The proportions of terminations in CA1' and CA1 were significantly higher than in the rest of the hippocampal subregions (four cases; one-way ANOVA with Bonferroni's post hoc test, $F_{(6,21)}=10.1, p \leq 0.003$ between $\mathrm{CA}^{\prime}$ and $\mathrm{CA} 2$, ProS, Sub, and DG; $p \leq 0.008$ between CA1 and CA2, ProS, Sub, and DG). CA3 showed a trend of a higher proportion of amygdalar boutons than CA2, DG, ProS, and Sub (Fig. 4C). Moreover, we found that $>80 \%$ of the amygdalar boutons terminated in the anterior half of hippocampus (Fig. $4 B$ ), where they preferentially targeted the SLM layer of CA1, CA3, and CA1' (Fig. 4E; CA1, $67.5 \pm 7 \%$; CA3, $72.1 \pm 5 \%$; $\mathrm{CAl}^{\prime}, 74.3 \pm 6 \%$ ). By comparison, there was a trend for fewer amygdalar boutons in the SLM layer in the posterior hippocampus (CA1, $42.6 \pm 7.8 \%$; CA3, $52.1 \pm 12.7 \%$ ), especially in CA1 
A
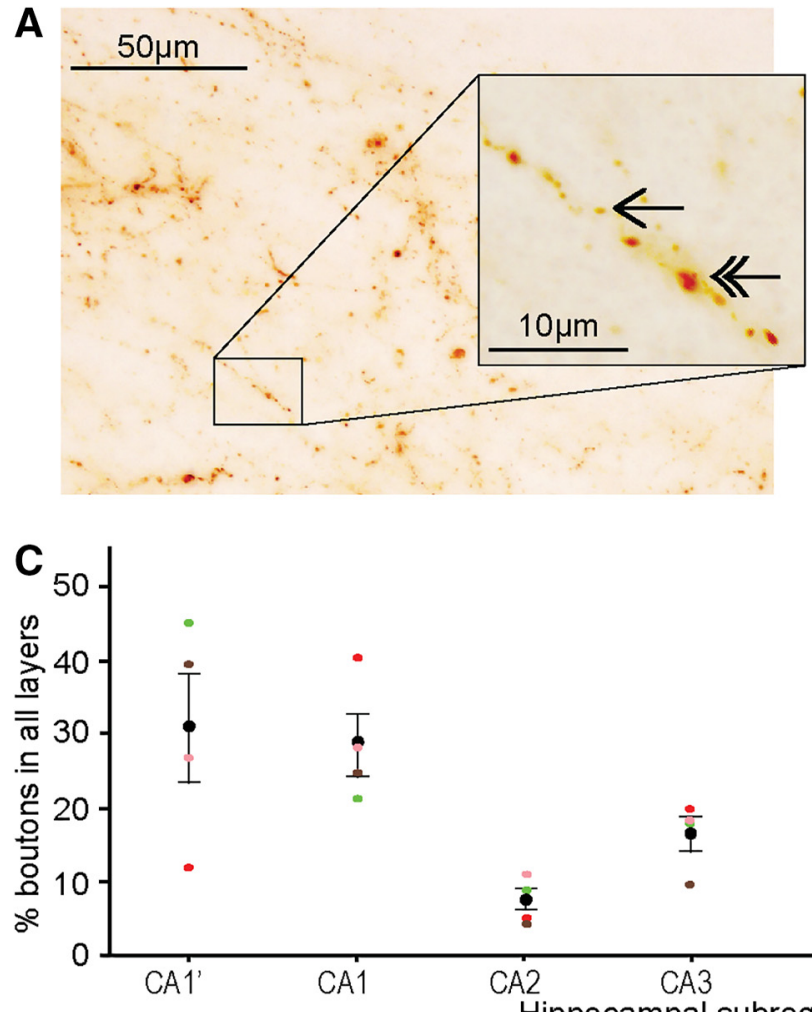

D

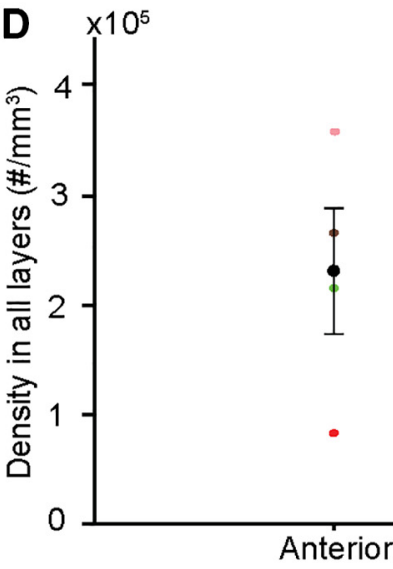

E

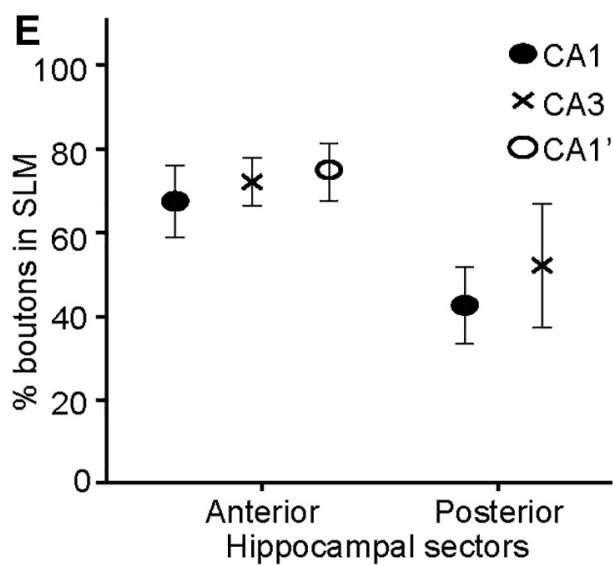

Hippocampal subregions

Middle
campal sectors

$\mathbf{F}$

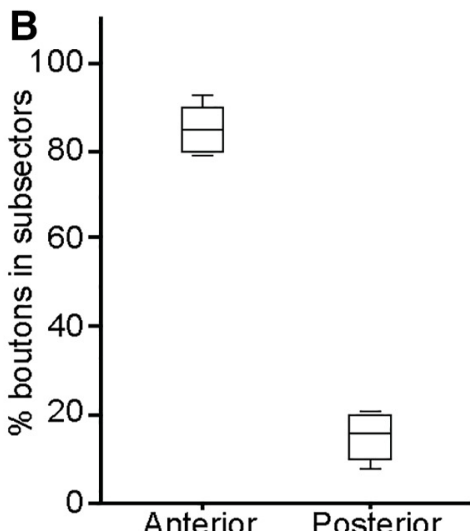

Hippocampal sectors

- case: BL

- case: BM

- case: BN

- case: BT
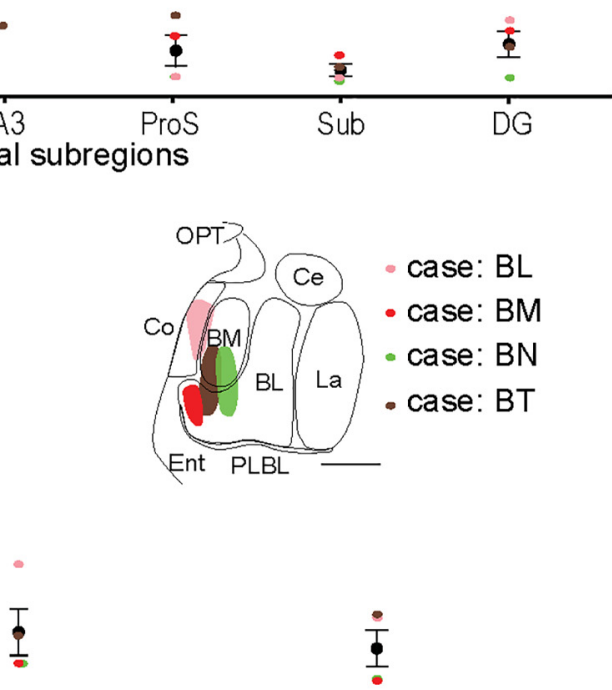

i்

Posterior

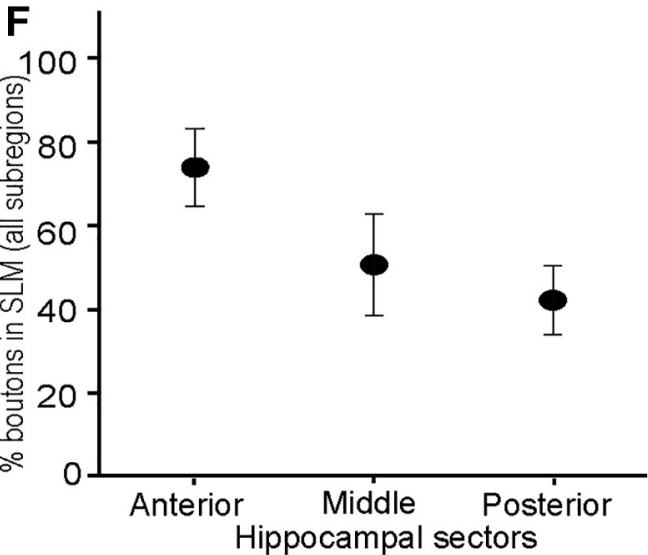

Figure 4. Stereologic analysis of amygdalar boutons in the hippocampus. A, Labeled amygdalar boutons in the hippocampus seen under bright-field illumination. The double head arrow points to a large bouton; the single head arrow points to a small bouton. $\boldsymbol{B}$, Box-plot of proportions of amygdalar boutons in the anterior vs posterior hippocampus. $\boldsymbol{C}$, Proportion of amygdalar boutons in each hippocampal subregion in all layers. D, Density of amygdalar boutons in the anterior middle and posterior sectors of the hippocampus. The inset in $\boldsymbol{D}$ shows the injection sites. Scale bar, $2 \mathrm{~mm}$.

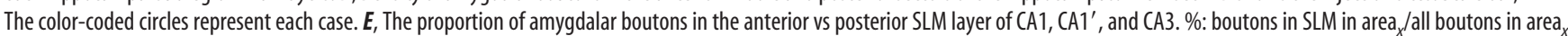
$\boldsymbol{F}$, The proportion of amygdalar boutons in the anterior, middle, and posterior SLM layer of CA1. Error bars indicate \pm SE. 

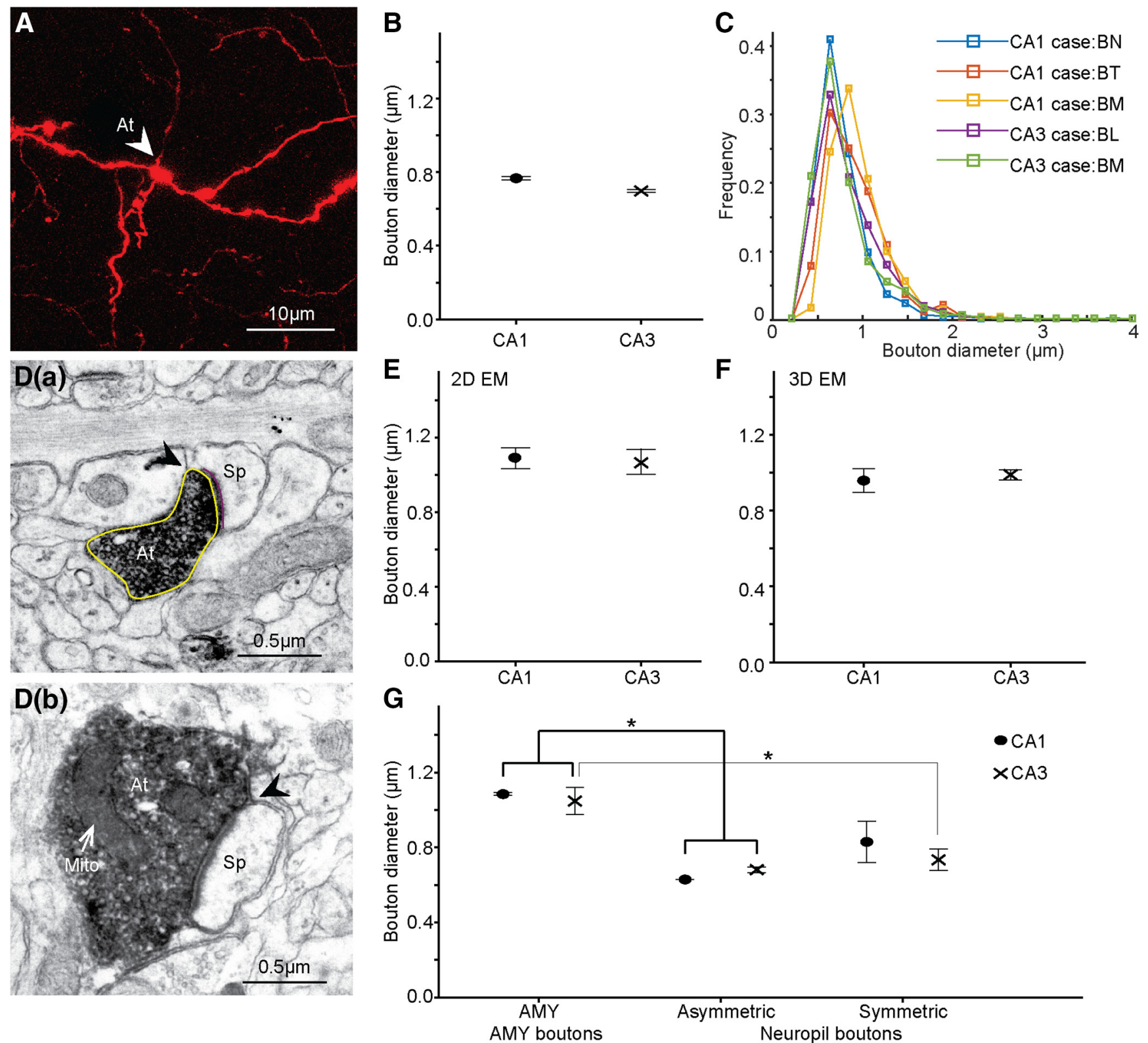

Figure 5. Amygdalar boutons in $C A 1$ and $C A 3$ have similar major diameters and are larger than asymmetric synapses in the surrounding neuropil. $A$, High-power confocal photomicrograph shows labeled bouton from an amygdalar axon (red, white arrowhead). Scale bar, $10 \mu \mathrm{m}$. B, Amygdalar boutons are similar in size (major diameter) in SLM layer of CA1 and CA3. C, Bouton major diameter frequency distributions in SLM layer CA1 and CA3 in individual cases. $D(a)$, Two examples of labeled amygdalar boutons: small bouton without mitochondria (yellow outline of bouton), purple line shows the PSD. D(b), Large bouton with mitochondria; black arrowheads point to synapses. At, Axon terminal; Mito, mitochondrion; Sp, spine. $\boldsymbol{E}$, $\boldsymbol{F}$, Similarity in bouton major bouton diameter in SLM of CA1 and CA3 with 2D and 3D EM. G, Amygdalar boutons (AMY) that form asymmetric (excitatory) synapses in CA1 or CA3 are significantly larger in diameter than asymmetric synapses in the surrounding neuropil. CA1, black oval; $C A 3$, cross. Error bars indicate \pm SE. ${ }^{*} p \leq 0.05$.

(two-tailed $t$ test, $t_{(6)}=1.997, p=0.093$ ). As shown in Figure $4 F$, the proportion of boutons in the SLM layer of CA1 was highest in anterior hippocampus, and decreased through the middle and posterior hippocampal sectors. A density analysis, which takes into account the volume of tissue sampled, revealed that the densest amygdalar terminations were found in the anterior hippocampus (Fig. 4D), which is consistent with results of the axon-tracing analysis described above. In summary, our findings showed that the amygdalar terminations were most prevalent in the SLM layer of $\mathrm{CA} 1, \mathrm{CAl}^{\prime}$, and $\mathrm{CA} 3$ in the anterior hippocampus.

The size of the amygdalar boutons is similar in CA1 and CA3 We then measured the size of amygdalar terminals in the hippocampus. This analysis is based on evidence that large boutons contain more synaptic vesicles, which correlate with the probability of multivesicular release upon stimulation (Stevens, 2004; Germuska et al., 2006). We first studied the major diameter of amygdalar boutons in the SLM layer of CA1 and CA3, which were the major targets of amygdalar terminations, of the anterior hippocampus. We measured the diameter of amygdalar terminations using confocal microscopy (Fig. 5A), and from images obtained from uninterrupted EM series of sections for 2D and 3D EM analyses (Fig. 5D). Results from the three independent methods showed comparable amygdalar bouton size (mean diameter in CA1: confocal microscopy, $0.76 \pm 0.05 \mu \mathrm{m}$, major diameter \pm SE; 2D EM, $1.05 \pm 0.0008 \mu \mathrm{m}$; 3D EM, $0.98 \pm 0.10 \mu \mathrm{m})$. Analysis yielded similar results on bouton size in CA3 (confocal level, $0.69 \pm 0.04 \mu \mathrm{m} ; 2 \mathrm{D} \mathrm{EM}, 1.13 \pm 0.03 \mu \mathrm{m}$; and 3D EM: $0.98 \pm$ 
$0.08 \mu \mathrm{m})$. Comparison of bouton size in CA1 and CA3 showed no significant differences (Fig. $5 B, C, E, F$; confocal microscopy: $n=5911$ boutons from four cases; major diameter; two-tailed $t$ test, $\left.t_{(2)}=0.108, p=0.924\right) ; 2 \mathrm{D}$ EM: $n=271$, from three cases; two-tailed $t$ test, $t_{(269)}=0.318, p=0.75$; and 3D EM: $n=234$, from two cases; two-tailed $t$ test, $\left.t_{(232)}=0.516, p=0.61\right)$. Frequency distribution analysis of bouton diameter across cases showed a similar distribution pattern in the SLM layer of CA1 and CA3 (Fig. 5C).

We then investigated whether amygdalar boutons forming synapses in hippocampus were similar to the surrounding neuropil or not. We found that the mean diameter of amygdalar boutons was significantly larger than those forming asymmetric (presumed excitatory) synapses in the surrounding neuropil in the SLM layer of both CA1 and CA3 (two-tailed $t$ test: $t_{(2)}=$ $59.406, p=0.000$ for CA1; $t_{(4)}=4.936, p=0.008$ for CA3; Fig. $5 G)$. Also, amygdalar boutons were larger in diameter than boutons in the neuropil making symmetric (presumed inhibitory) synapses in SLM of CA3 (two-tailed $t$ test, $t_{(4)}=3.382, p=0.03$ ), but not in the SLM layer of CA1 (two-tailed $t$ test, $t_{(2)}=2.329$, $p=0.145$; Fig. $5 G$ ).

Synaptic efficacy is determined by both presynaptic and postsynaptic features. We thus used serial-section EM analyses to study bouton volume, the presence of mitochondria at the presynaptic sites, PSD surface area, and the presence of perforated PSD at the postsynaptic sites, all of which are correlated with synaptic efficacy (Stevens, 2004; Bourne and Harris, 2008; Medalla and Luebke, 2015). The PSD is correlated with the density of AMPA receptors (Bourne and Harris, 2008; Nava et al., 2014), and perforated synapses increase the PSD surface area (Geinisman, 1993; Desmond and Weinberg, 1998; Medalla and Luebke, 2015). Reconstruction of amygdalar boutons showed that volumes were similar in the SLM layer of CA1 and CA3 (two-tailed $t$ test, $t_{(2)}=-1.312, p=0.32$; Fig. $6 A$ ). Moreover, a bouton may contain mitochondria, a feature associated with activity level (Thomson, 2000). More than $60 \%$ of the amygdalar boutons contained mitochondria in both CA1 and CA3 (Figs. 5D, 6C). This is consistent with the above data that amygdalar boutons are larger than excitatory boutons in the surrounding neuropil. The PSD surface areas for amygdalar terminations were comparable in the SLM layer of CA1 and CA3 $\left(_{(2)}=-3.868 ; p=0.061\right.$; Fig. $6 B)$, as was the proportion of perforated synapses in CA1 and CA3 (CA1, 15.4\%; CA3, 7.6\%; two-tailed $t$ test, $t_{(3)}=3.001, p=$ 0.058; Fig. 6D).

We then investigated the relationships between PSD surface area and bouton volume or diameter. The analyses revealed that among amygdalar boutons in CA1 and CA3, PSD surface area was significantly correlated with bouton volume (linear regression: $n=202$ boutons, $\left.R^{2}=0.43, F_{(1,200)}=151.811, p=0.000\right)$ and with bouton diameter (linear regression: $n=202, R^{2}=$ $0.222, F_{(1,200)}=57.344, p=0.000$; Fig. $\left.6 E, F\right)$. In summary, the measurements of the structural features of the amygdalar terminations in the SLM layer of CA1 and CA3 were similar, and the size of the amygdalar boutons was larger than the excitatory boutons in the surrounding neuropil.

\section{The inhibitory microenvironment of the hippocampus}

We next investigated whether amygdalar terminals innervate some inhibitory neurons in the hippocampus. Among inhibitory neurons, those that express PV are fast-spiking neurons; they innervate perisomatic elements of pyramidal neurons and thus can exert strong inhibition. Another group of neurons labeled by CR forms synapses on inhibitory neurons and thus disinhibits downstream pyramidal neurons in both rats and monkeys (Kawaguchi et al., 1987; Gulyás et al., 1992; Ribak et al., 1993; Sik et al., 1995). However, calbindin is expressed in both pyramidal and nonpyramidal neurons in the hippocampus (Seress et al., 1991; Tóth and Freund, 1992), and thus is not a reliable marker for inhibitory neurons.

It is unknown whether $\mathrm{CR}$ and $\mathrm{PV}$ are expressed exclusively in inhibitory neurons in the primate hippocampus, as shown for the cortex (DeFelipe, 1997). We thus labeled tissue sections for PV or $\mathrm{CR}$ and double labeled the tissue sections for GABA, a universal inhibitory neuron marker. We found that among $\mathrm{PV}^{+}$neurons in the hippocampus, 98\% coexpressed GABA, and among all $\mathrm{CR}^{+}$neurons, $87 \%$ were double labeled with GABA (Fig. 7A). In most hippocampal subregions, $>90 \%$ of the $\mathrm{CR}^{+}$neurons coexpressed GABA, except in the DG, where a significant proportion of non-GABAergic $\mathrm{CR}^{+}$neurons were found in the pcl layer $\left(\mathrm{CR}^{+} \mathrm{GABA}^{+}=68.8 \pm 8.01 \%\right.$; four cases; Fig. $\left.7 \mathrm{~B}, \mathrm{C}\right)$. The nonGABAergic $\mathrm{CR}^{+}$neurons resembled mossy cells, described in mice and primates (Freund and Buzsáki, 1996; Amaral et al., 2007; Scharfman and Myers, 2012).

We then studied the proportion of $\mathrm{PV}^{+}$and $\mathrm{CR}^{+}$neurons among GABAergic neurons and their distribution. Among all GABAergic neurons in the hippocampus, $14.9 \%$ were $\mathrm{PV}^{+}$and $40.8 \%$ were $\mathrm{CR}^{+}$(PV, two cases; $\mathrm{CR}$, four cases; Fig. 7D). Studies have shown that PV and CR are not coexpressed in the same neuron in the hippocampi of rats or primates (Miettinen et al., 1992; Seress et al., 1993a). In combination, $\mathrm{PV}^{+}$and $\mathrm{CR}^{+}$neurons thus represent more than half of all GABAergic neurons in the hippocampus.

As shown in Figure 8, $\mathrm{CR}^{+}$and $\mathrm{PV}^{+}$neurons were distributed in distinct layers of the hippocampus. $\mathrm{CR}^{+}$neurons occupied mainly the SLM and RAD layers (upper layers) of CA3 and CA1. In contrast, $\mathrm{PV}^{+}$neurons predominated in the PCL and $\mathrm{OR}$ layers (deep layers; Figs. 7E, 8). $\mathrm{PV}^{+}$and $\mathrm{CR}^{+}$neurons thus both are reliable markers of inhibitory neurons and are expressed in complementary layers in the primate hippocampus, especially in CA1 and CA3.

\section{The postsynaptic targets of amygdalar terminations in hippocampus}

Double labeling to view amygdalar pathways and inhibitory neurons

We then double labeled hippocampal sections with tracer and CR or PV to study whether amygdalar terminations targeted these classes of inhibitory neurons in CA1 and CA3. Analysis based on confocal microscopy showed that $3.5 \%$ of amygdalar terminations were apposed with elements of $\mathrm{CR}^{+}$neurons in the SLM layer of CA1 ( $n=4653$; four cases), but none were apposed with $\mathrm{PV}^{+}$neurons (Fig. 9A-C). In contrast, in the SLM layer of CA3, amygdalar terminations contacted elements of both $\mathrm{CR}^{+}(3.1 \%$, $n=2130$, two cases $)$ and $\mathrm{PV}^{+}(4.5 \%, n=2818$, two cases) neurons (Fig. 9C). This is consistent with our finding that no PV label could be detected in the SLM layer of CA1, but $\mathrm{PV}^{+}$label was seen in the SLM of CA3 (Fig. 8). By comparison, amygdalar terminations were apposed with a comparable proportion of $\mathrm{CR}^{+}$neurons in CA1 and CA3 $\left(\chi^{2}\right.$ test, $\chi_{(1,6831)}^{2}=0.677, p=$ $0.44)$.

The preference of amygdalar pathways for specific hippocampal subregions was confirmed at the synaptic level using serialsection EM (Fig. 9D-G). There was no evidence that amygdalar terminations formed synapses with $\mathrm{PV}^{+}$profiles in SLM of CA1 ( $n=79$ synapses, one case), but some contacted $\mathrm{PV}^{+}$profiles in 

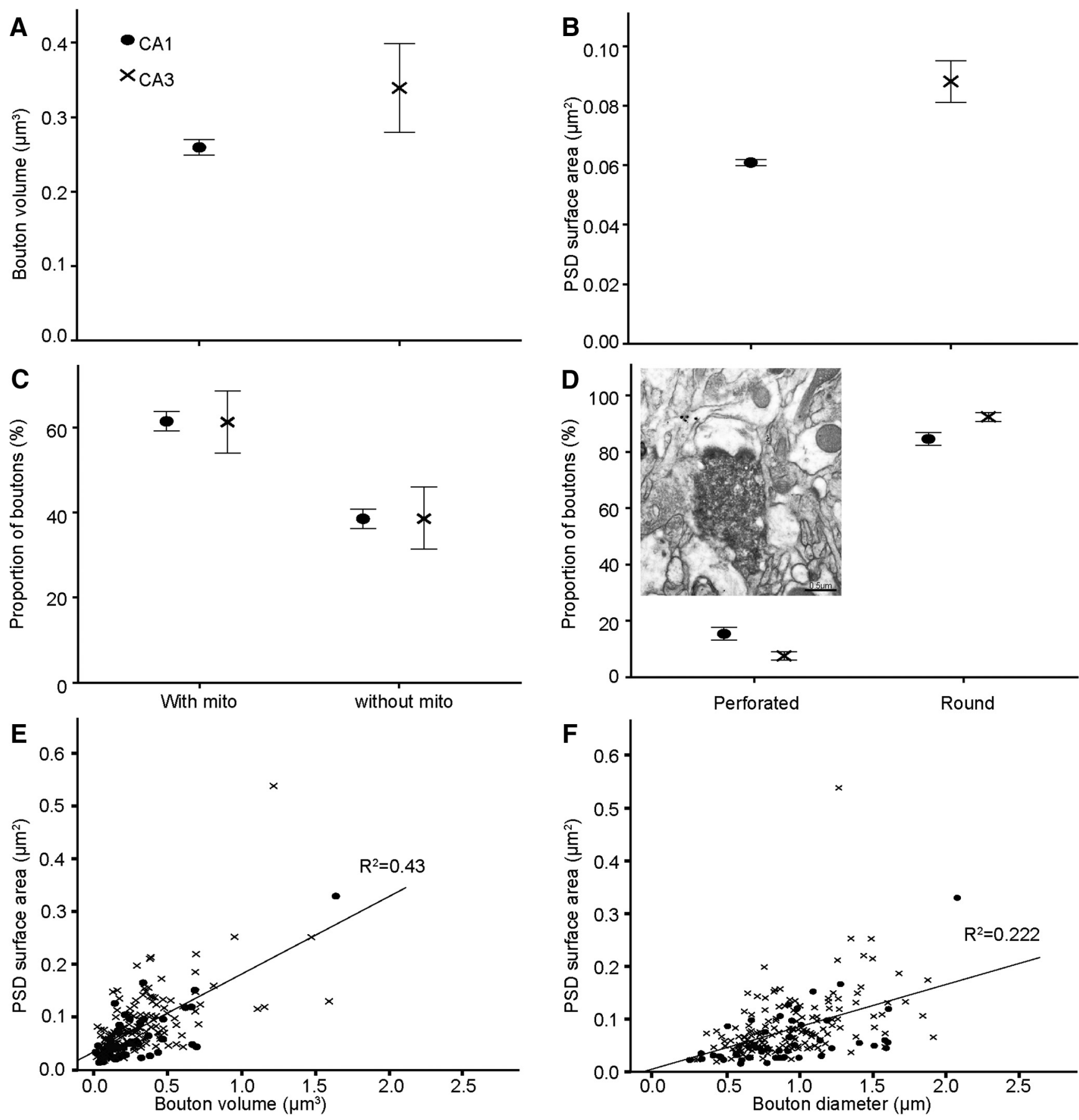

Figure 6. Similarity of presynaptic and postsynaptic features of amygdalar boutons in SLM of CA1 and CA3. A, B, Amygdalar bouton volume and PSD surface area in CA1 and CA3. C, Proportion of amygdalar boutons with mitochondria (with mito) and without mitochondria (without mito) in CA1 and CA3. D, Proportion of amygdalar boutons that formed perforated and round synapses in CA1 and CA3. Inset, Example of a perforated synapse (m-shaped PSD). $E$, Relationship of PSD surface area to bouton volume in CA1 and CA3 for all cases. $\boldsymbol{F}$, Relationship of PSD surface area to bouton diameter in CA1 and CA3 for all cases. CA1, black oval; CA3, cross. Error bars indicate \pm SE.

the SLM layer of CA3 (mean \pm SE, $1.8 \pm 0.9 \% ; n=162$ synapses; three cases; Fig. 9G). In CA3, amygdalar boutons terminated on $\mathrm{PV}^{+}$dendritic shafts. A similar proportion of amygdalar boutons formed synapses on $\mathrm{CR}^{+}$profiles in CA1 and CA3 (CA1: $4.4 \pm$ $0.02 \%, n=136$ synapses, two cases; CA3: $2.6 \pm 0.2 \%, n=124$ synapses, two cases; $\chi_{(1,260)}^{2}=0.77, p=0.50$; Fig. $\left.9 G\right)$. In both $\mathrm{CA} 1$ and CA3, about half of the amygdalar boutons that innervated inhibitory postsynaptic sites terminated on $\mathrm{CR}^{+}$spines, and the other half contacted $\mathrm{CR}^{+}$dendritic shafts (Fig. $9 D, E$ ).
Morphologic analysis to identify excitatory and universal inhibitory postsynaptic sites

We used serial-section EM to probe further amygdalar boutons as they innervated postsynaptic targets in the anterior hippocampus in the SLM layer of CA1 and CA3, which were the major targets of the amygdala. Synapses on excitatory or inhibitory neurons can be identified reliably using morphologic criteria (Peters et al., 1991). Only boutons that formed synapses were included in the analysis. The amygdalar pathway could be divided into four 
A

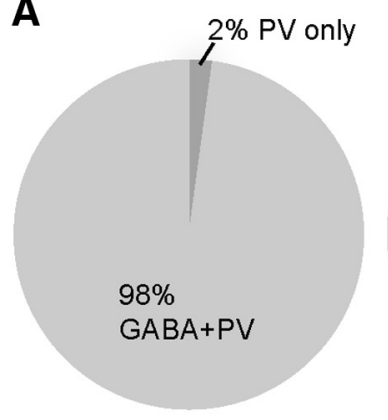

C
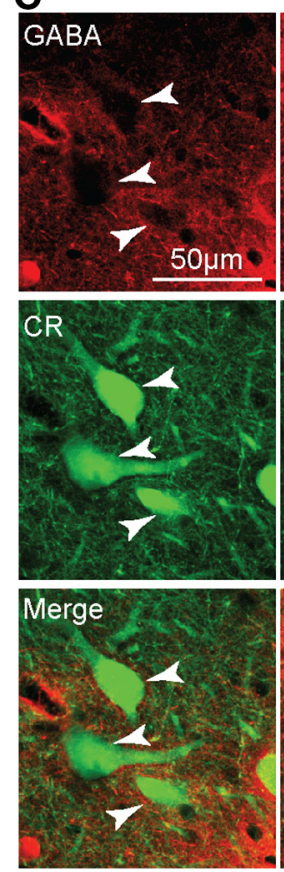

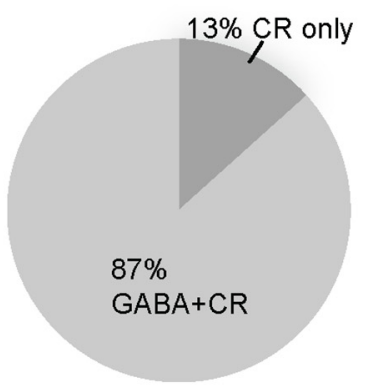

$87 \%$

$B A+C R$
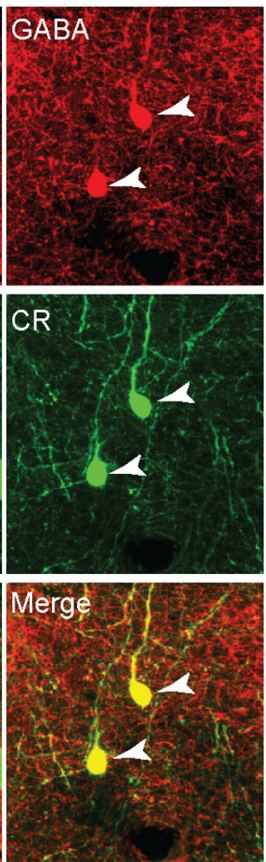
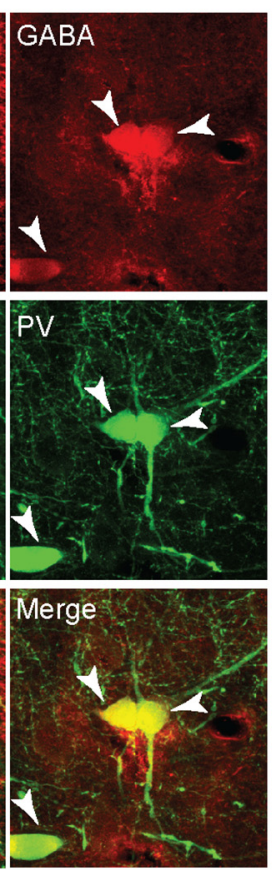

B
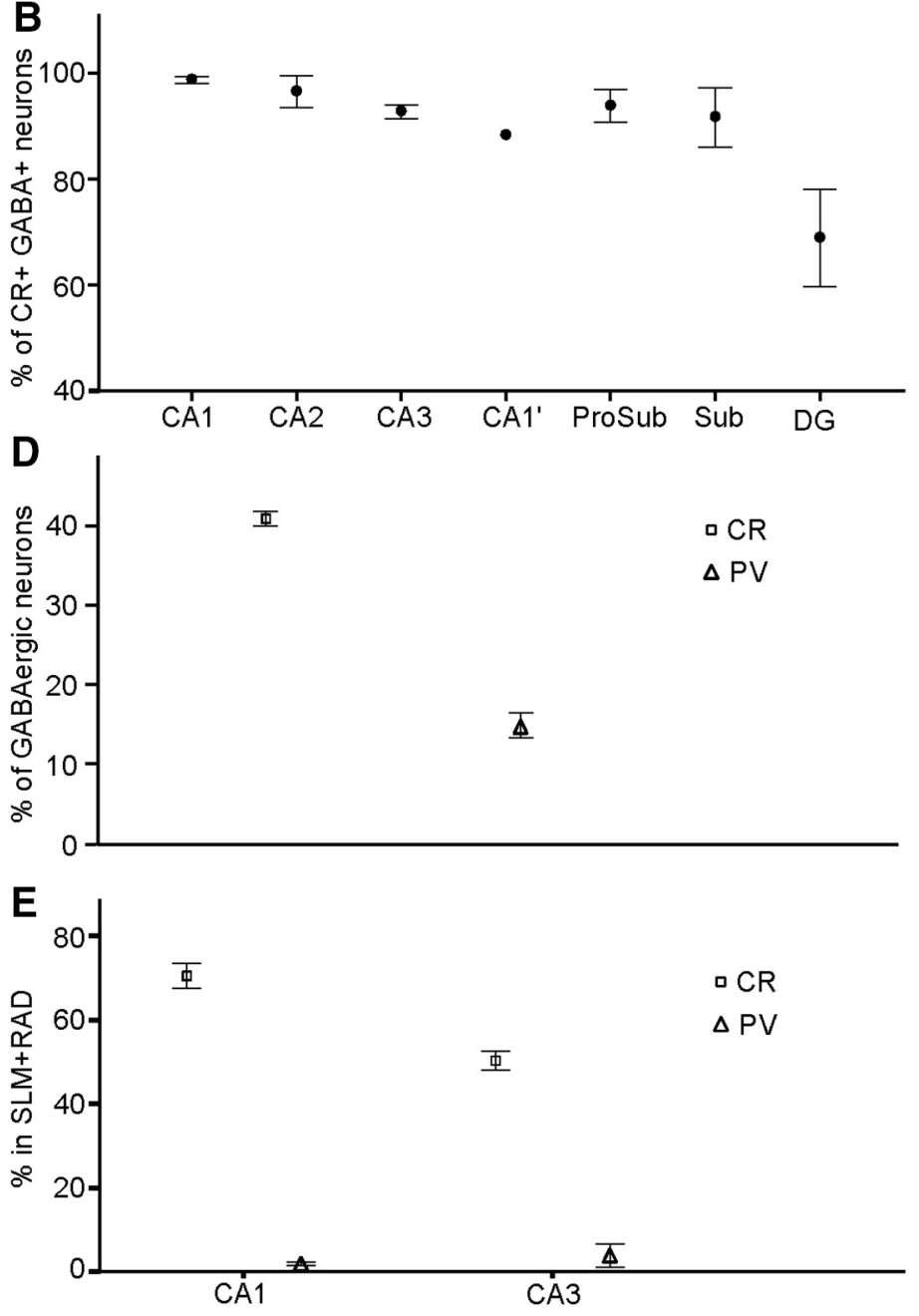

Figure 7. $\mathrm{PV}^{+}$and $C \mathrm{R}^{+}$neurons coexpress $\mathrm{GABA}$ and have different distribution patterns in hippocampal subregions. $\boldsymbol{A}$, Pie charts show the proportion of $\mathrm{GABAergic} P{ }^{+}$neurons vs non-GABAergic $P V^{+}$neurons (left), and for $C R$ (right). $B, C R^{+}$neurons that are also positive for $G A B A$ as a proportion of all $C R^{+}$neurons in each hippocampal subregion. $C$, Examples of $C R^{+}$and $\mathrm{PV}^{+}$neurons that coexpress GABA. Left panels: $\mathrm{CR}^{+} \mathrm{GABA}^{-}$neurons in the $\mathrm{DG}$ are presumably excitatory mossy cells. Middle panels: $\mathrm{CR}^{+} \mathrm{GABA}^{+}$neurons. Right panels: $\mathrm{PV}{ }^{+} \mathrm{GABA}^{+}$neurons. Scale bar, $50 \mu \mathrm{m}$. D, Normalized proportion of GABAergic neurons that coexpress CR (square) or PV (triangle). $\boldsymbol{E}_{,} \mathrm{CR}^{+}$(square) and PV ${ }^{+}$(triangle) neurons in the upper layers (SLM + RAD) in CA1 and $C A 3$, expressed as a proportion of all $C R^{+}$and PV ${ }^{+}$neurons in $C A 1$ and $C A 3$. The complement for each point corresponds to neurons found in the deep layers (PCL $+0 R$; data not shown). Error bars indicate $\pm S E$.

categories by their postsynaptic targets on: spines, dendritic shafts, multiple synaptic sites on the same targets (all on spines or on dendritic shafts), and on different postsynaptic targets (on spine and dendritic shaft; Fig. 10A,B). Most amygdalar boutons formed synapses with dendritic spines from putative spiny excitatory neurons that were not labeled with either PV or CR (CA1: $76 \%, n=242$ synapses, two cases; CA3: $80 \%, n=323$ synapses, three cases). A smaller but significant number of amygdalar boutons innervated dendritic shafts in the hippocampus (CA1: $13.9 \%$, two cases; CA3: 10.4\%, three cases). A few labeled boutons formed multiple synapses with more than one structure (Fig. $10 B, C)$.

Low spine density on dendrites and high synapse density on dendritic shafts are reliable morphologic features of inhibitory neurons in the cortex of primates (Peters et al., 1991). We thus also used morphologic features in $3 \mathrm{D}$ EM to test the possible inhibitory nature of profiles innervated by the amygdala that were labeled for PV or CR, or were unlabeled. Previous findings in rats (Megías et al., 2001) showed that the dendrites of pyramidal neurons in the SLM layer of hippocampus contain spines (density, $0.4-1.7$ spines/ $\mu \mathrm{m}$ ) and only occasionally receive asymmetric synapses on dendritic shafts (density, 0.09-0.11 synapses/ $\mu \mathrm{m})$. In this study, all $\mathrm{PV}^{+}$dendritic shafts that received amygdalar inputs were aspiny, indicating that they belonged to inhibitory neurons. Most of the dendritic shafts innervated by the amygdala were aspiny. A few contained spines but also received unlabeled asymmetric synapses on the dendritic shafts (density for unlabeled synapses, $0.2-0.6$ synapse/ $\mu \mathrm{m}$ ), a morphologic feature suggesting that the dendritic shafts belonged to inhibitory neurons. Most amygdalar boutons that innervated $\mathrm{CR}^{+}$neurons had spine density ranging from 0.5 to 2.2 spines/ $\mu \mathrm{m}$, and had unlabeled asymmetric synapses on their dendritic shafts ranging from 0.3 to 0.5 synapses $/ \mu \mathrm{m}$. Based on the morphologic analysis and our finding that $>90 \%$ of the $\mathrm{CR}^{+}$neurons in CA1 and CA3 coexpress GABA (Fig. 7B), we concluded that the $\mathrm{CR}^{+}$dendrites that received amygdalar axon boutons most likely belonged to inhibitory neurons.

Our analysis showed that $\mathrm{PV}^{+}$and $\mathrm{CR}^{+}$neurons are reliable markers of inhibitory neurons in the macaque monkey hippocampus. Using serial-section EM and morphologic analysis, 


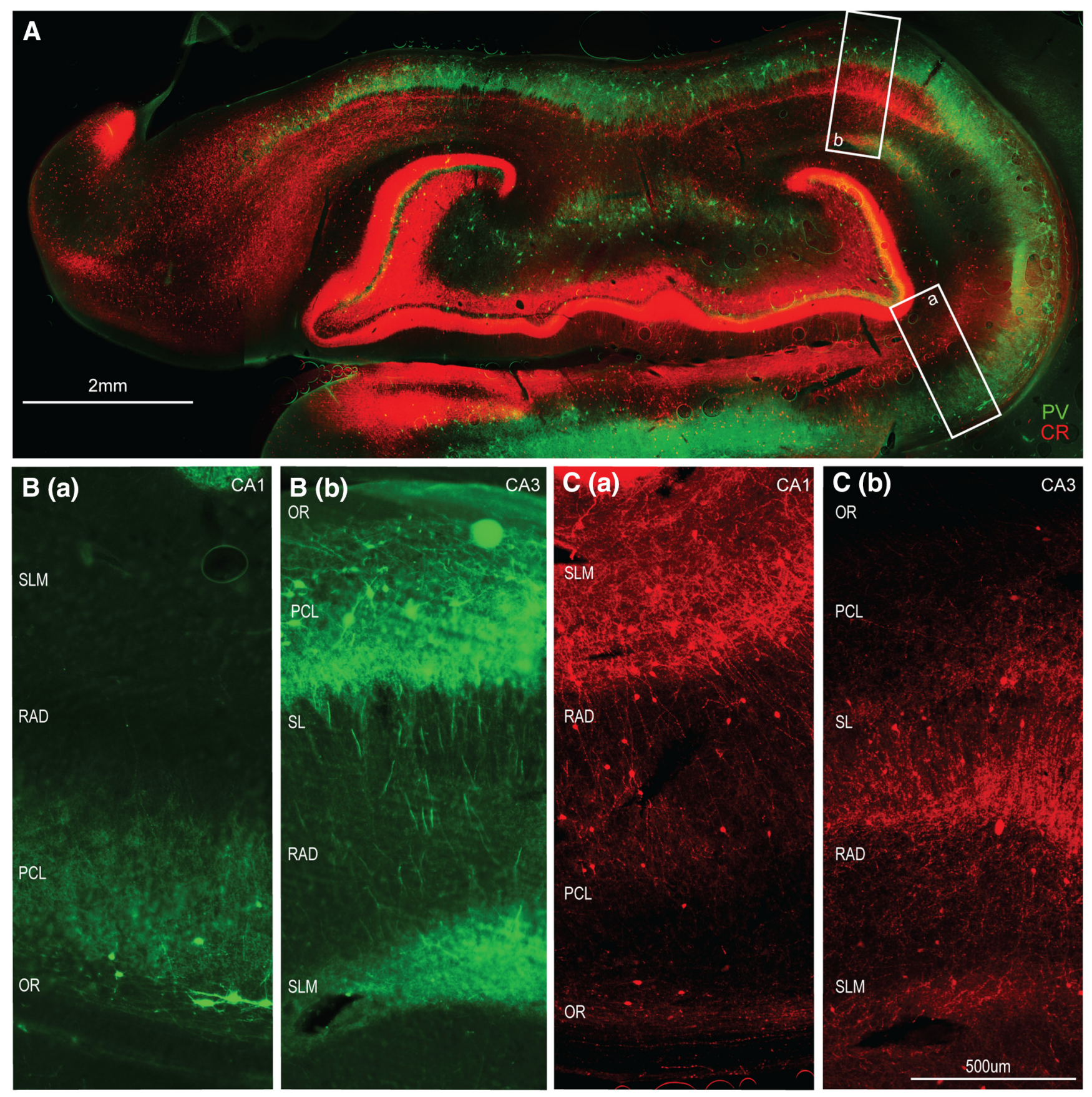

Figure 8. Complementary distribution of $\mathrm{CR}^{+}$and $\mathrm{PV}^{+}$neurons in the hippocampus. $A$, Immunofluorescence photomicrograph of two adjacent superimposed sections labeled with $C \mathrm{R}^{+}$(red) or $\mathrm{PV}^{+}$(green). Scale bar, $2 \mathrm{~mm} . \boldsymbol{B}(\boldsymbol{a}), \boldsymbol{B}(\boldsymbol{b})$, Single label of $\mathrm{PV}^{+}$neuron distribution in $C A 1[B(\boldsymbol{a})]$ and $C A 3[B(b)] . C(a), C(b)$, Single label of $C \mathrm{R}^{+}$neuron distribution in $C A 1[C(a)]$ and $C A 3[C(b)]$. $B, C$, The higher-magnification photomicrographs were taken from the respective single-labeled sections at the level of the white-boxed areas in $\boldsymbol{A}$. Scale bar, $500 \mu \mathrm{m}$.

we found that amygdalar terminations formed synapses on dendritic shafts of presumed inhibitory neurons in CA1 (13.9\%) and CA3 (10.4\%). Since PV and CR represent nonoverlapping groups of inhibitory neurons in primates (Seress et al., 1991, 1993a,b), we then subtracted the percentage of amygdalar boutons that terminated on dendritic shafts of $\mathrm{PV}^{+}$and $\mathrm{CR}^{+}$inhibitory neurons from the percentage of amygdalar terminations on putative inhibitory neurons evaluated by morphologic criteria (by synapses on dendritic shafts). This calculation showed that $\sim 11.7 \%$ of amygdalar boutons in CA1 and 7.3\% in CA3 formed synapses on dendritic shafts that did not express either PV or CR. The morphologic evidence suggests that these dendrites belong to inhibitory neurons that express $\mathrm{CB}$ or somatostatin, as described for rats and mice (for review, see Klausberger, 2009; Pelkey et al., 2017).

\section{Distinct features of the amygdalar pathways to hippocampus} revealed with $\mathrm{EM}$

We used long series of EM sections (number, 37-296) to reconstruct amygdalar axons and the dendrites they innervated. We found that some amygdalar axons in SLM layer of CA1 and CA3 formed single as well as dual synapses on the same dendritic segment. The amygdalar boutons that formed single synapses fell into the following two categories: type 1, single-bouton axons 

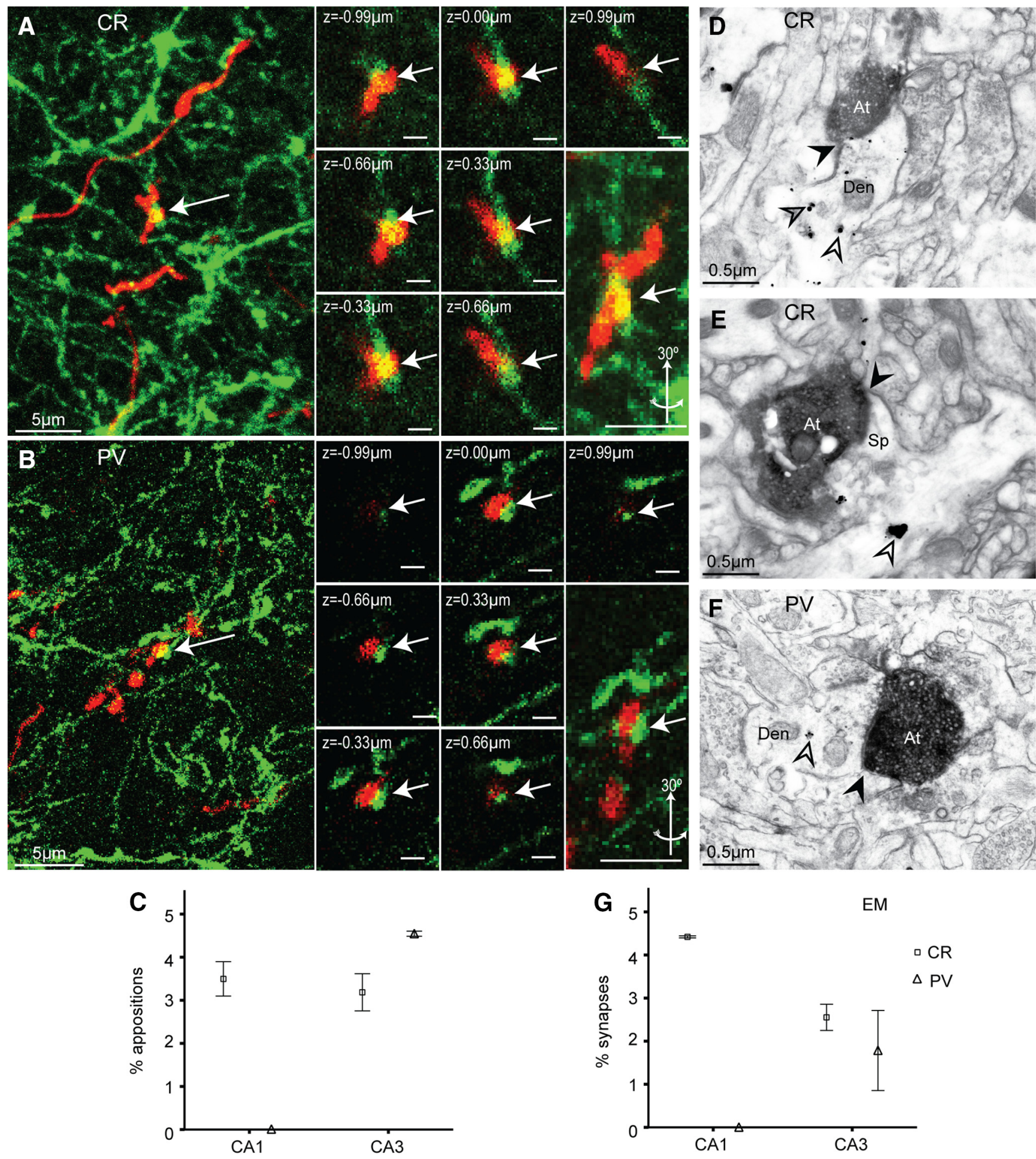

Figure 9. Relationship between amygdalar terminations and inhibitory neurons in SLM of CA1 and CA3. $A, B$, Left panels, Immunofluorescence shows amygdalar terminations (red) apposed with $\mathrm{CR}^{+}$dendrites (green, $\boldsymbol{A}$ ) and $\mathrm{PV}{ }^{+}$dendrites (green, $\boldsymbol{B}$ ). Scale bar, $5 \mu \mathrm{m} . \boldsymbol{A}, \boldsymbol{B}$, Right panels, Serial sections and $3 \mathrm{D}$ rotation of the apposition sites; white arrows point to apposition sites. Scale bar, $1 \mu \mathrm{m}$. C, Plots show the proportion of amygdalar terminations apposed on $\mathrm{CR}^{+}$or $\mathrm{PV}^{+}$elements in SLM of CA1 and CA3 (immunofluorescence). The amygdalar terminations formed appositions with $\mathrm{PV}^{+}$elements (triangles) only in SLM of CA3. D, E, Examples of amygdalar boutons that form synapses on $\mathrm{CR}^{+}$dendritic shafts (D; Den) and CR ${ }^{+}$spine $(\boldsymbol{E} ; \mathrm{Sp})$ labeled with gold (silhouette arrowheads). $\boldsymbol{F}$, Example of amygdalar bouton with a synapse on $\mathrm{PV}^{+}$dendritic shaft (Den) labeled with gold. Black arrowheads point to the synaptic sites. At, Axon terminal; Den, dendritic shaft; Sp, dendritic spine. G, Proportion of amygdalar boutons that form synapses on $\mathrm{CR}^{+}$or PV ${ }^{+}$elements in SLM of CA1 and CA3 (EM). In C and G: CR, squares; PV, triangles. Error bars indicate \pm SE.

that formed a synapse only once in the EM stacks; and type 2, two or more boutons from the same axon formed multiple synapses in the EM stacks (Fig. 11A). About $53.9 \%$ of the labeled amygdalar boutons in CA3 SLM belonged to the second type. This proportion was lower $(20.9 \%)$ in SLM of CA1. Moreover, type 2 boutons could be further subdivided into the following two subtypes: 2a, boutons on the same axon formed synapses on disconnected dendritic segments (Fig. 11A, right); and 2b, boutons from the same axon formed close synapses on the same dendritic segment (dual-boutons; Fig. 11A, left). Among type 2 boutons in 

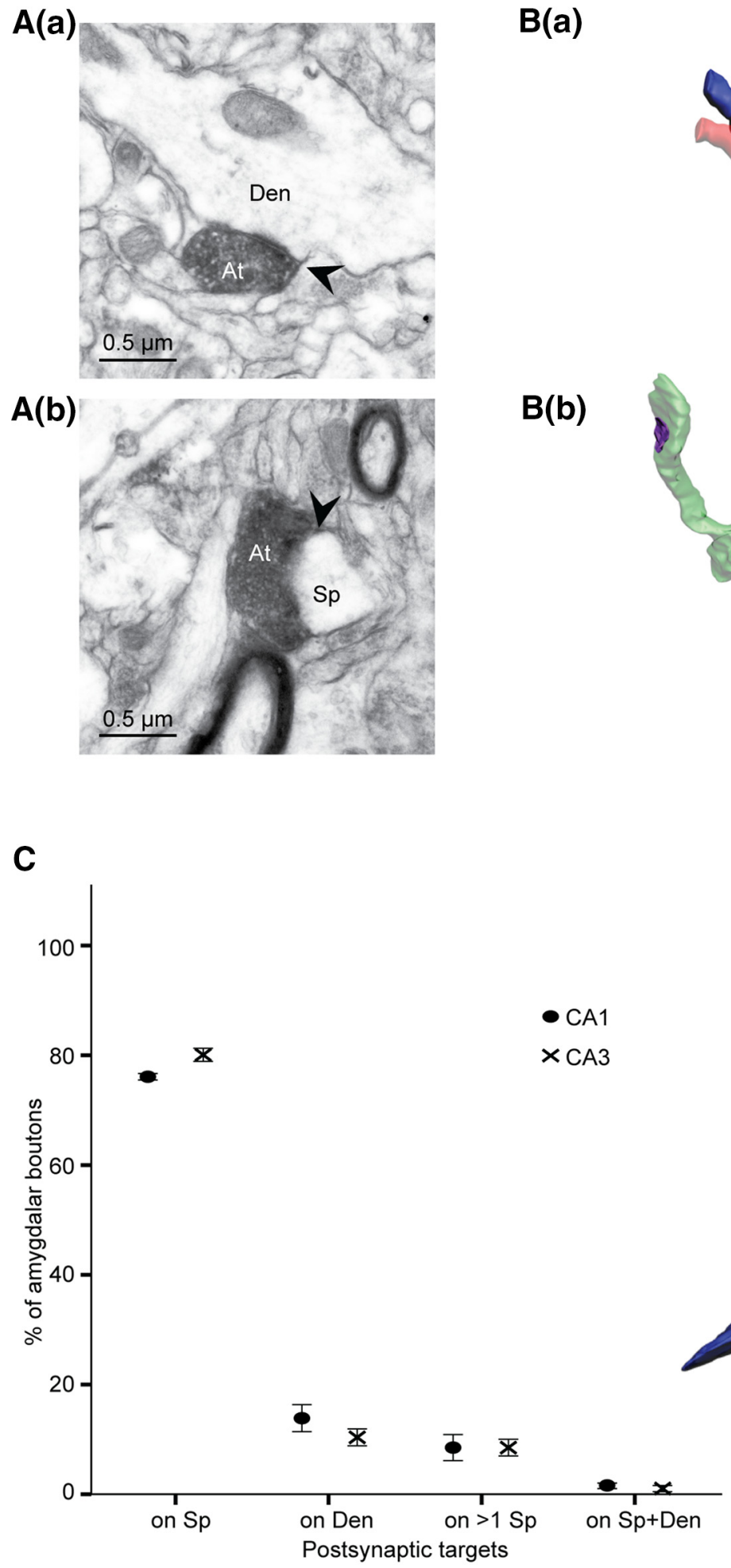

Figure 10. Postsynaptictargets of amygdalar terminations in CA1 and CA3.A(a), $A(b)$, EM photomicrographs of DAB labeled boutons (At) that formed synapses with a dendritic shaft (Den) $[A(a)]$ and a spine (Sp) $[\boldsymbol{A}(\boldsymbol{b})]$. Arrowheads point to the PSD. $\boldsymbol{B}(\boldsymbol{a})-\boldsymbol{B}(\boldsymbol{d})$, 3D reconstruction of labeled amygdalar axons (blue), their postsynaptic targets (green, spiny dendrites; red, aspiny dendrites), and their PSD (yellow). The arrowheads point to the amygdalar PSD; PSDs formed by unlabeled boutons are shown in purple. Amygdalar bouton with synapses on the following: dendritic shaft [B(a)]; spine $[\boldsymbol{B}(\boldsymbol{b})]$; two spines $[\boldsymbol{B}(\boldsymbol{c})]$; and spine and dendrite $[\boldsymbol{B}(\boldsymbol{d})]$. Gray boxes show scale: $0.5 \times 0.5 \times 0.5 \mu \mathrm{m}$. $\boldsymbol{C}$, The proportion of amygdalar boutons that formed synapses with distinct postsynaptic targets in SLM of CA1 (black oval) and CA3 (cross). Error bars indicate \pm SE.

the SLM of CA3, 38\% boutons fell into the dual-bouton subtype, $\sim 58 \%$ boutons were of the first subtype, while the rest ( $\sim 4.2 \%$ boutons) could not be categorized because they were on the edge of the EM stack. The dual boutons usually were found within $\sim 30$ EM sections $(\sim 50 \mathrm{~nm}$ each), and the distance be- tween bases of the two spines that received synapses from the same axon ranged from 1.14 to $5.71 \mu \mathrm{m}$. In contrast, we did not find dual boutons in SLM of CA1. Thus, the amygdalar axons were more likely to form double contacts with a given CA3 dendritic segment than in CA1. 


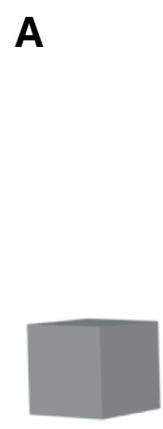

B
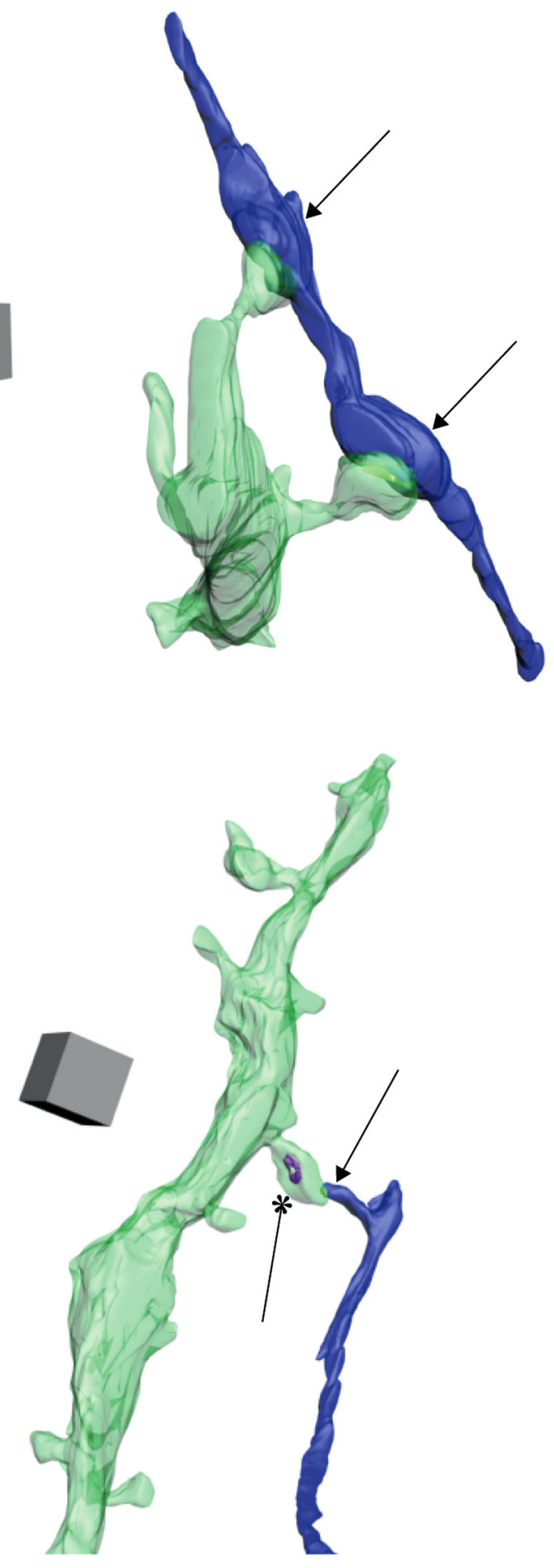
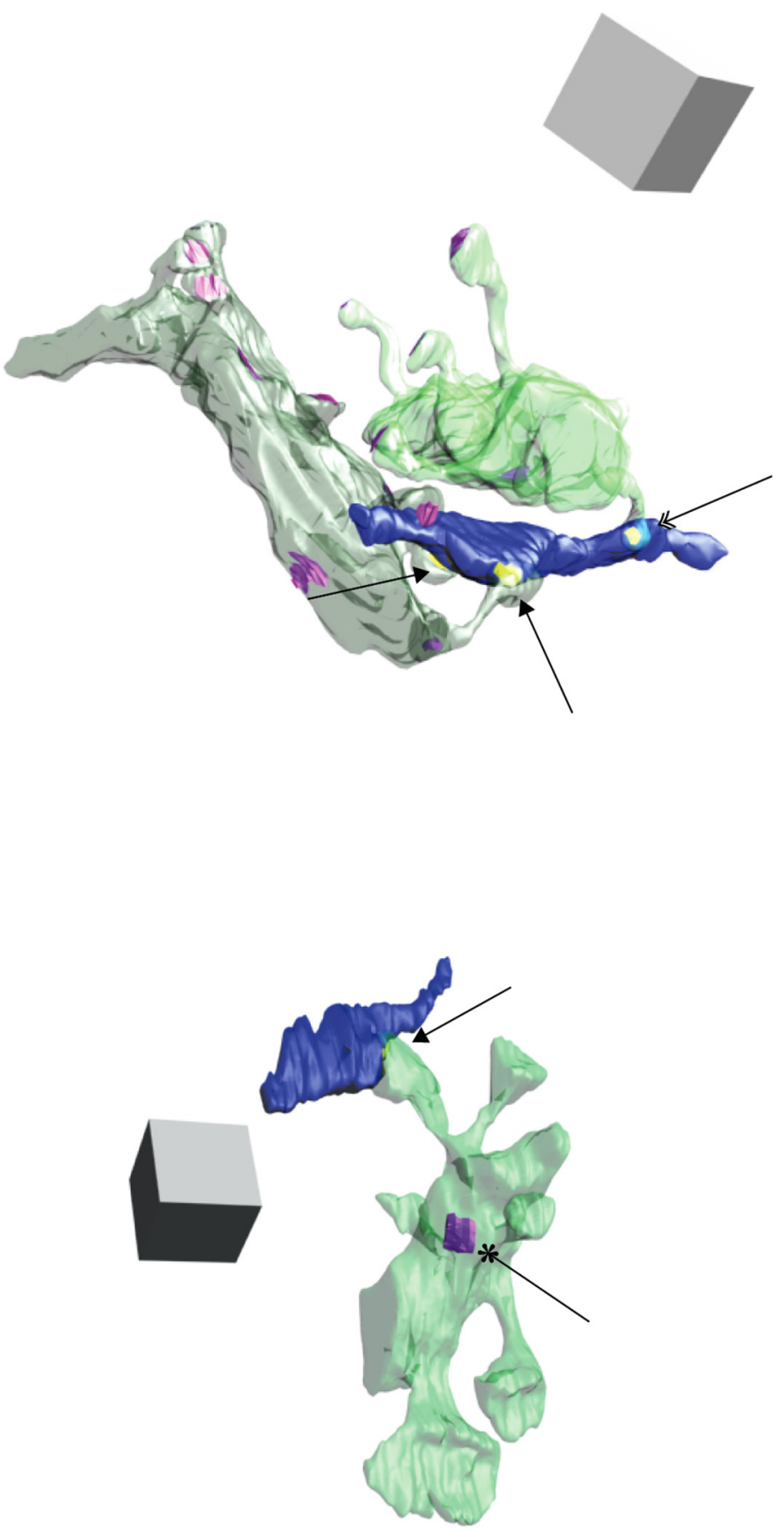

Figure 11. Special features of amygdalar synapses with postsynaptic targets. $A$, Type 2 boutons (description in Results). Left, Dual boutons (blue) on one axon form synapses with two spines (green) on the same dendritic segment (black arrows). Right, One axon formed two boutons: one formed a synapse with a spine (double head arrow); and the other formed two synapses on spines coming from the same dendritic segment (black arrows). $\boldsymbol{B}$, Two examples of spines that received amygdalar terminations and also formed another synapse with unlabeled boutons on the spine neck (left; purple, star), or a spine base (right). Black arrows point to amygdalar synapses. Stars point to synapses with unlabeled boutons (PSD in purple). Blue, Amygdalar axons; green, dendrites; yellow, amygdalar PSD; purple, unlabeled bouton PSD. Gray boxes show scale: $1 \times 1 \times 1 \mu \mathrm{m}$.

In another pattern of innervation, single amygdalar boutons formed multiple synapses on the same dendritic segment in SLM of CA1 ( $\sim 38 \%$ of boutons) and CA3 (20\% of boutons; Fig. $11 \mathrm{~A}$, right, dark green dendrite). The distance between bases of the two spines that received synapses from the same bouton ranged from 1.07 to $3.10 \mu \mathrm{m}$ in CA1, and was closer in CA3 (0.88 to $0.92 \mu \mathrm{m})$. Moreover, $>80 \%$ of axon terminations from amygdala to the SLM layer of CA1 and CA3 were en passant. This finding suggests that amygdalar terminations can make focused synapses on the same dendritic compartments in the SLM layer of CA3.

Synapses formed in the proximity of the synaptic site of a given bouton are thought to strongly influence the activity of each other (Jones and Powell, 1969). We thus reconstructed the synapses formed near the postsynaptic targets of amygdalar boutons in the SLM layer of CA3. About 50\% (38 of 78 boutons) of postsynaptic sites targeted by the amygdala received another syn- 
apse close by. These synapses appeared on the spine neck or head (Fig. 11B, left) or close to the base of the spine (Fig. 11B, right). Interestingly, most ( 25 of 38 boutons) of these synapses were asymmetric, and presumably represent excitatory inputs from other brain regions. There was also a significant number ( 13 of 38 boutons) of inhibitory synapses close to the amygdalar termination sites on the spine neck and spine base, suggesting a modulatory role. These boutons from inhibitory axons did not belong to either $\mathrm{PV}^{+}$or $\mathrm{CR}^{+}$neurons.

\section{Discussion}

We found that amygdalar pathways innervated the entire hippocampus, but unevenly: the large majority of terminals innervated the anterior hippocampus and preferentially targeted the upper layers, which were positioned to influence the input to hippocampus. Sparser amygdalar terminations in posterior hippocampus innervated the deep layers, suggesting influence on the output of hippocampus. The amygdala innervated some CR inhibitory neurons in CA1, but in CA3 it innervated both CR and some of the powerful PV neurons. These specific pathways position the amygdala to influence differentially dynamic rhythms for a variety of processes, including reinforcement learning and memory within an affective or social context, and disruption in disease.

\section{Amygdalar inputs target different layers along the longitudinal axis of hippocampus}

The specificity of amygdalar pathways included innervation of the SLM layer in anterior hippocampus, and the RAD and PCL of the proximal ProS and distal CA1 in posterior hippocampus. In rats, as in primates, the amygdala projects to the anterior hippocampus (ventral in rodents). At the laminar level, however, the rat pattern differs, by predominant termination in the RAD and OR layers (Pikkarainen et al., 1999; Pitkänen et al., 2000; Petrovich et al., 2001; McDonald and Mott, 2017).

The predominant amygdalar innervation of SLM in anterior hippocampus coincides with terminations of perforant pathways from entorhinal cortex, noted for a role in affective contextual memory in rats, mice, and primates (Steward and Scoville, 1976; Witter and Amaral, 1991; Kjelstrup et al., 2002; Poppenk et al., 2013; Strange et al., 2014; Zeidman and Maguire, 2016). In contrast, amygdalar terminations in posterior hippocampus targeted the distal CA1 and proximal ProS, where neurons project out of the hippocampus (Rosene and Van Hoesen, 1977). Our findings thus suggest that the amygdalar pathways impinge on the entire longitudinal hippocampal axis, influencing signal inflow to hippocampus anteriorly, and outflow posteriorly.

\section{Pathways from the amygdala to hippocampus are strong}

Amygdalar boutons in the SLM layer of CA1 and CA3 were larger than unlabeled boutons that formed synapses in the surrounding neuropil. Large bouton size is correlated with a high probability of neurotransmitter release (Rosenmund and Stevens, 1996; Murthy et al., 1997; Germuska et al., 2006). Moreover, $>60 \%$ of amygdalar boutons contained mitochondria, which are found in large boutons that have high activity (Vaughn and Grieshaber, 1972; Pierce and Mendell, 1993; Pierce and Lewin, 1994; Thomson, 2000; Zikopoulos and Barbas, 2007).

However, unlike other large boutons in corticocortical connections, or even rhinal pathways to hippocampus in rats or monkeys (Geinisman, 1993; Megías et al., 2001; Nicholson et al., 2006; Bunce et al., 2013; Nava et al., 2014; Medalla et al., 2017), we found a relatively low proportion of perforated amygdalar syn- apses in CA3 and CA1. Perforated synapses increase PSD surface area and, consequently, the number of receptors, allowing more neurotransmitter binding during multiquantal release (Matsuzaki et al., 2001; Raghavachari and Lisman, 2004). Previous studies have shown that quantal release of neurotransmitter is sufficient to saturate AMPA receptors within a postsynaptic area of $\sim 0.04-0.05 \mu \mathrm{m}^{2}$ (Franks et al., 2003; Raghavachari and Lisman, 2004; Medalla and Luebke, 2015). In our material, the PSD surface area of amygdalar boutons was $0.06 \mu \mathrm{m}^{2}$ in CA1 and 0.08 $\mu \mathrm{m}^{2}$ in CA3, suggesting that it can saturate after release of two vesicles. The presynaptic and postsynaptic structures thus are closely matched in this primate system.

\section{Specialized synaptic features of amygdalar pathways may facilitate oscillatory events in hippocampus}

Electrical stimulation of the rat basolateral amygdalar nucleus elicits synchrony between CA3 and CA1 in the low-gamma range (30-55 Hz; Bass et al., 2012, 2014; Bass and Manns, 2015), a rhythm also recorded in the human amygdala during emotional arousal (Pagano and Gault, 1964; Oya et al., 2002; Sato et al., 2011, 2013). Since gamma synchrony is correlated with successful memory encoding in humans, macaques, and rats (Fell et al., 2001; Sederberg et al., 2007; Jutras et al., 2009; Trimper et al., 2017), the robust amygdalar terminations in CA1 and CA3 may facilitate this process.

An additional specialization in the amygdalar pathway was the formation of dual synapses by amygdalar axons on the same dendritic segment of excitatory neurons, seen exclusively in CA3, a site that gives rise to sharp-wave ripples in rats (Buzsáki, 1986; Chrobak and Buzsáki, 1994). Sharp potentials recorded in amygdala during sleep or under anesthesia suggest the transmission of synchronized outputs in cats, mice, and rats (Paré et al., 1995; Collins and Paré, 1999; Bocchio et al., 2017; Girardeau et al., 2017). Synchronized discharge in $\sim 10 \%$ of CA3 pyramidal neurons appears to be sufficient to elicit sharp-wave ripples (Csicsvari et al., 2000). The dual amygdalar contacts in CA3 thus may be sufficient to convey strong excitation on small groups of pyramidal neurons to initiate sharp-wave ripples, facilitating the consolidation of salient events.

\section{The amygdala innervates specific inhibitory neurons in different fields: functional implications}

Amygdalar boutons formed exclusively asymmetric (excitatory) synapses in hippocampus, resembling other long-distance projections of the primate amygdala (Miyashita et al., 2007; Timbie and Barbas, 2014, 2015). In SLM of CA1, most amygdalar terminations contacted spines of pyramidal neurons and some $\mathrm{CR}^{+}$ neurons, which have a key role in disinhibiting pyramidal neurons in rats and primates (Gulyás et al., 1996; Urbán et al., 2002; Tóth et al., 2010). This evidence suggests a predominant excitatory effect of the amygdala in CA1 (Fig. 12A), facilitating learning and memory within an affective or social context in primates (Cahill et al., 1995, 1996; Cahill and McGaugh, 1998; Packard and Teather, 1998; Hamann et al., 1999; Wellman et al., 2016; Inman et al., 2018).

In the SLM of CA3, amygdalar axons formed synapses on excitatory pyramidal neurons and $\mathrm{CR}^{+}$neurons, as in CA1. However, the amygdalar pathway to CA3 showed yet another specialization: innervation of some $\mathrm{PV}^{+}$inhibitory neurons, which provide strong perisomatic inhibition of nearby pyramidal neurons in primates and rodents (Leranth and Ribak, 1991; Seress et al., 1991; Ribak et al., 1993; Freund and Buzsáki, 1996; Papp et al., 2013). Interestingly, optogenetic stimulation of $\mathrm{PV}^{+}$ 


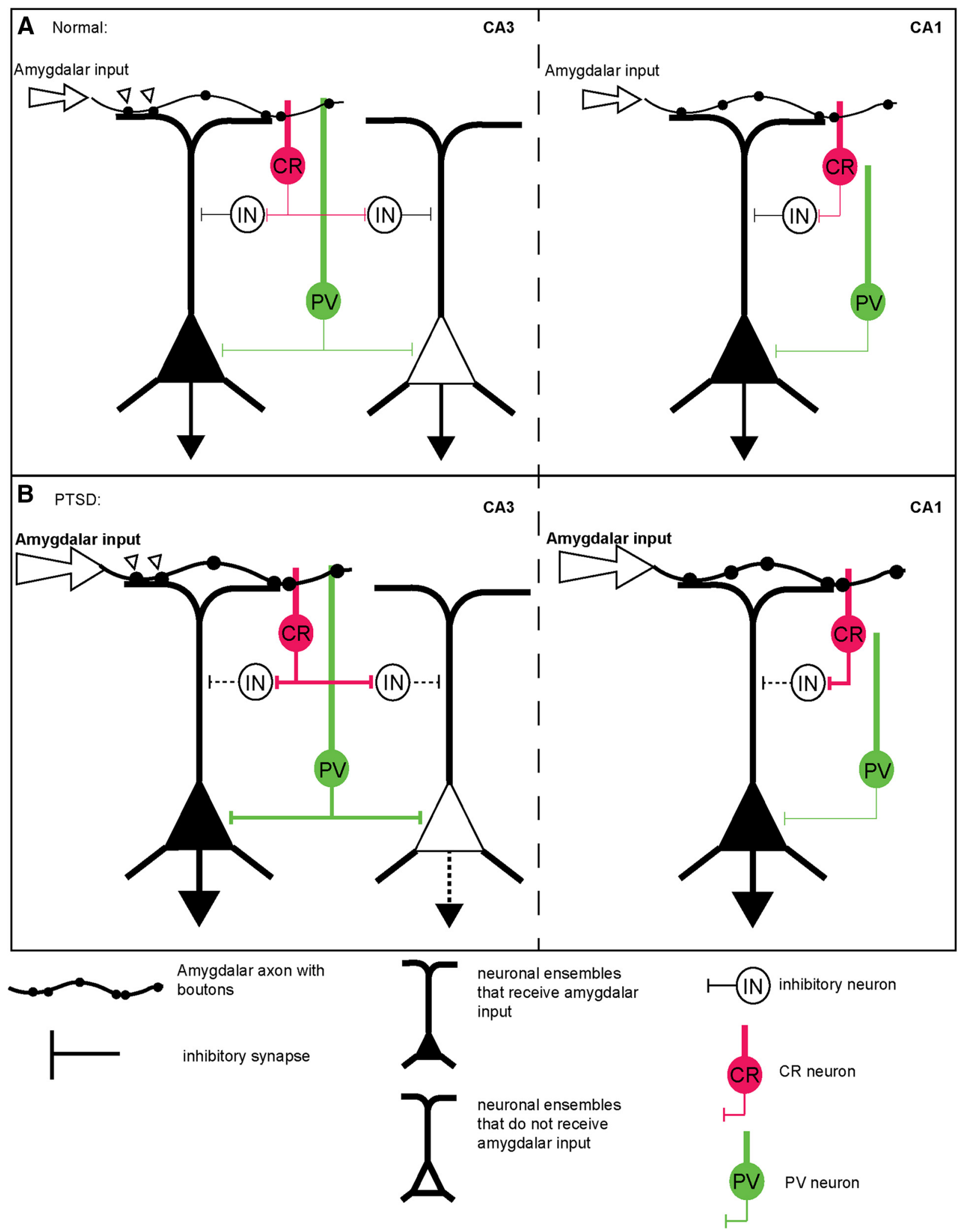

Figure 12. Summary scheme of features of amygdalar inputs to CA1 and CA3 and proposed normal function and imbalance in PTSD. $A$, In CA3, amygdalar axons contact both CR ${ }^{+}$and PV ${ }^{+}$ neurons, which may balance the activity of pyramidal neurons under normal conditions. In CA1, amygdalar axons contact $\mathrm{CR}^{+}$neurons and pyramidal neurons and enhance memory-related processes. $\boldsymbol{B}$, In the PTSD state, only the CA3 pyramidal neurons that receive strong amygdalar input can be activated, while others that receive input from different sources (but not from the amygdala) are inhibited by the strong nearby PV neurons, which are activated by the amygdala. Synapses by afferent inputs from other sources on neurons in the surrounding neuropil are likely weaker than the amygdalar synapses, as shown by the analysis of synapses in the surrounding neuropil. Consequently, excessive excitation from the amygdala may result in the loss of information in CA3, leading to less specific and more generalized representations of affective context and fear-related stimuli. This pattern may be facilitated by the dual amygdalar synapses found on the same segment of dendrites of excitatory neurons (white triangles). 
neurons in CA3 in mice initiates sharp-wave ripples, while suppression of $\mathrm{PV}^{+}$neurons eliminates them (Schlingloff et al., 2014).

The patterns of amygdalar pathways to CA1 and CA3 are summarized in a circuit model in Figure 12. The combined innervation of $\mathrm{CR}^{+}$and $\mathrm{PV}^{+}$neurons in CA3 suggests excitatory and inhibitory effects on pyramidal neurons. This pattern may allow the firing of pyramidal neurons that both do and do not receive amygdalar terminations (Fig. 12A). Since CA3 is crucial for the formation of associative memory in rodents and humans (McNaughton and Morris, 1987; Nakazawa et al., 2002; Lee et al., 2004; Bakker et al., 2008; Lacy et al., 2010; Langston et al., 2010), proper firing of CA3 pyramidal neurons ensures the establishment of correct associations between behaviorally relevant cues from the amygdala and other sources (Fig. 12A).

The anterior hippocampus is affected in post-traumatic stress disorder (PTSD), reflecting abnormalities in network connections for encoding, retrieval, and consolidation of contextual information, leading to fear generalization in rodents and humans (Phillips and LeDoux, 1992; Shin et al., 2006; Maren et al., 2013; Liberzon and Abelson, 2016; Abdallah et al., 2017; Akiki et al., 2017). Figure $12 B$ shows a possible circuit mechanism for fear generalization, based on excessive input from the amygdala during traumatic events. A strong surge of affective-related input from the amygdala may lead to a strong drive of excitatory neurons in both CA1 and CA3, as well as $\mathrm{PV}^{+}$neurons in CA3. In mice, hyperactivation of $\mathrm{PV}^{+}$neurons in the ventral hippocampus enhances the propagation of sharp-wave ripples from CA3 to CA1, leading to persistent fear (Çaliskan et al., 2016). By analogy, during high emotional arousal the amygdala likely strongly activates the powerful PV neurons in CA3, which then can shut down the activity of nearby pyramidal neurons that do not receive amygdalar input and have comparatively smaller synapses from inputs from other sources, as revealed by neuropil analysis here. The specialized wiring thus may create a filter through $\mathrm{PV}^{+}$neurons in $\mathrm{CA} 3$, so that only pyramidal neurons that receive strong amygdalar input can overcome neighboring inhibition and remain active, resulting in fear generalization (Fig. 12B). The activation of pyramidal neurons in CA3 may also be enhanced by the closely spaced dual-amygdalar synapses on the same dendritic segment, found here.

The circuit model of strong and highly specific input from amygdala to the primate hippocampus uncovered here provides the synaptic mechanism to help explain how high activation of the amygdala leads to increased connectivity in anterior hippocampus between CA3 and CA1 in PTSD in humans (Duncan et al., 2014; Diamond and Zoladz, 2016; Liberzon and Abelson, 2016; Abdallah et al., 2017). CA3 has a critical role for the retrieval of memories (Manns and Eichenbaum, 2006; Koene and Hasselmo, 2008). During excessive arousal, there may be a shift from external assessment of the environment via hippocampal-cortical connections to dominance of processing of the internal milieu in rodents and primates (Manns and Eichenbaum, 2006; Koene and Hasselmo, 2008; Duncan et al., 2014; Abdallah et al., 2017). The specialized wiring features from amygdala to hippocampus thus may lead to abnormal consolidation of affective-related cues under high emotional upheaval leading to the re-experience of trauma in PTSD.

\section{References}

Abdallah CG, Wrocklage KM, Averill CL, Akiki T, Schweinsburg B, Roy A, Martini B, Southwick SM, Krystal JH, Scott JC (2017) Anterior hippocampal dysconnectivity in posttraumatic stress disorder: a dimensional and multimodal approach. Transl Psychiatry 7:e1045. CrossRef Medline
Akiki TJ, Averill CL, Wrocklage KM, Schweinsburg B, Scott JC, Martini B, Averill LA, Southwick SM, Krystal JH, Abdallah CG (2017) The association of PTSD symptom severity with localized hippocampus and amygdala abnormalities. Chronic Stress (Thousand Oaks). Advance online publication. Retrieved August 8, 2017. doi:10.1177/2470547017724069.

Allsop SA, Vander Weele CM, Wichmann R, Tye KM (2014) Optogenetic insights on the relationship between anxiety-related behaviors and social deficits. Front Behav Neurosci 8:241. CrossRef Medline

Amaral D, Lavenex P (2006) Hippocampal neuroanatomy. In: The hipppocampus book (Andersen P, Morris R, Amaral D, Bliss T, O’Keefe J, eds), pp 37-114. Oxford, UK: Oxford UP.

Amaral DG, Insausti R (1990) Hippocampal formation. In: The human nervous system (Paxinos G, ed), pp 711-756. San Diego, CA: Academic.

Amaral DG, Scharfman HE, Lavenex P (2007) The dentate gyrus: fundamental neuroanatomical organization (dentate gyrus for dummies). Prog Brain Res 163:3-22. CrossRef Medline

Bakker A, Kirwan CB, Miller M, Stark CE (2008) Pattern separation in the human hippocampal CA3 and dentate gyrus. Science 319:1640-1642. CrossRef Medline

Bakst I, Amaral DG (1984) The distribution of acetylcholinesterase in the hippocampal formation of the monkey. J Comp Neurol 225:344-371. CrossRef Medline

Barbas H, Blatt GJ (1995) Topographically specific hippocampal projections target functionally distinct prefrontal areas in the rhesus monkey. Hippocampus 5:511-533. CrossRef Medline

Bass DI, Manns JR (2015) Memory-enhancing amygdala stimulation elicits gamma synchrony in the hippocampus. Behav Neurosci 129:244-256. CrossRef Medline

Bass DI, Nizam ZG, Partain KN, Wang A, Manns JR (2014) Amygdalamediated enhancement of memory for specific events depends on the hippocampus. Neurobiol Learn Mem 107:37-41. CrossRef Medline

Bass DI, Partain KN, Manns JR (2012) Event-specific enhancement of memory via brief electrical stimulation to the basolateral complex of the amygdala in rats. Behav Neurosci 126:204-208. CrossRef Medline

Bergstrom HC (2016) The neurocircuitry of remote cued fear memory. Neurosci Biobehav Rev 71:409-417. CrossRef Medline

Bocchio M, Nabavi S, Capogna M (2017) Synaptic plasticity, engrams, and network oscillations in amygdala circuits for storage and retrieval of emotional memories. Neuron 94:731-743. CrossRef Medline

Bourne JN, Harris KM (2008) Balancing structure and function at hippocampal dendritic spines. Annu Rev Neurosci 31:47-67. CrossRef Medline

Bunce JG, Zikopoulos B, Feinberg M, Barbas H (2013) Parallel prefrontal pathways reach distinct excitatory and inhibitory systems in memoryrelated rhinal cortices. J Comp Neurol 521:4260 - 4283. CrossRef Medline

Buzsáki G (1986) Hippocampal sharp waves: their origin and significance. Brain Res 398:242-252. CrossRef Medline

Cahill L, Babinsky R, Markowitsch HJ, McGaugh JL (1995) The amygdala and emotional memory. Nature 377:295-296. CrossRef Medline

Cahill L, Haier RJ, Fallon J, Alkire MT, Tang C, Keator D, Wu J, McGaugh JL (1996) Amygdala activity at encoding correlated with long-term, free recall of emotional information. Proc Natl Acad Sci U S A 93:8016-8021. CrossRef Medline

Cahill L, McGaugh JL (1998) Mechanisms of emotional arousal and lasting declarative memory. Trends Neurosci 21:294-299. CrossRef Medline

Çaliskan G, Müller I, Semtner M, Winkelmann A, Raza AS, Hollnagel JO, Rösler A, Heinemann U, Stork O, Meier JC (2016) Identification of parvalbumin interneurons as cellular substrate of fear memory persistence. Cereb Cortex 26:2325-2340. CrossRef Medline

Chamberland S, Topolnik L (2012) Inhibitory control of hippocampal inhibitory neurons. Front Neurosci 6:165. CrossRef Medline

Chrobak JJ, Buzsáki G (1994) Selective activation of deep layer (V-VI) retrohippocampal cortical neurons during hippocampal sharp waves in the behaving rat. J Neurosci 14:6160-6170. CrossRef Medline

Collins DR, Paré D (1999) Reciprocal changes in the firing probability of lateral and central medial amygdala neurons. J Neurosci 19:836-844. CrossRef Medline

Csicsvari J, Hirase H, Mamiya A, Buzsáki G (2000) Ensemble patterns of hippocampal CA3-CA1 neurons during sharp wave-associated population events. Neuron 28:585-594. CrossRef Medline

Daumas S, Halley H, Francés B, Lassalle JM (2005) Encoding, consolidation, and retrieval of contextual memory: differential involvement of dor- 
sal CA3 and CA1 hippocampal subregions. Learn Mem 12:375-382. CrossRef Medline

DeFelipe J (1997) Types of neurons, synaptic connections and chemical characteristics of cells immunoreactive for calbindin-D28K, parvalbumin and calretinin in the neocortex. J Chem Neuroanat 14:1-19. CrossRef Medline

Desmedt A, Marighetto A, Richter-Levin G, Calandreau L (2015) Adaptive emotional memory: the key hippocampal-amygdalar interaction. Stress 18:297-308. CrossRef Medline

Desmond NL, Weinberg RJ (1998) Enhanced expression of AMPA receptor protein at perforated axospinous synapses. Neuroreport 9:857-860. CrossRef Medline

Diamond DM, Zoladz PR (2016) Dysfunctional or hyperfunctional? the amygdala in posttraumatic stress disorder is the bull in the evolutionary china shop. J Neurosci Res 94:437-444. CrossRef Medline

Duncan K, Tompary A, Davachi L (2014) Associative encoding and retrieval are predicted by functional connectivity in distinct hippocampal area CA1 pathways. J Neurosci 34:11188-11198. CrossRef Medline

Eichenbaum H (2017) Prefrontal-hippocampal interactions in episodic memory. Nat Rev Neurosci 18:547-558. CrossRef Medline

Felix-Ortiz AC, Tye KM (2014) Amygdala inputs to the ventral hippocampus bidirectionally modulate social behavior. J Neurosci 34:586-595. CrossRef Medline

Fell J, Klaver P, Lehnertz K, Grunwald T, Schaller C, Elger CE, Fernández G (2001) Human memory formation is accompanied by rhinal-hippocampal coupling and decoupling. Nat Neurosci 4:1259-1264. CrossRef Medline

Fiala JC (2005) Reconstruct: a free editor for serial section microscopy. J Microsc 218:52-61. CrossRef Medline

Franks KM, Stevens CF, Sejnowski TJ (2003) Independent sources of quantal variability at single glutamatergic synapses. J Neurosci 23:3186-3195. CrossRef Medline

Freund TF, Buzsáki G (1996) Interneurons of the hippocampus. Hippocampus 6:347-470. Medline

García-Cabezas MÁ, Barbas H (2017) Anterior cingulate pathways may affect emotions through orbitofrontal cortex. Cereb Cortex 27:4891-4910. CrossRef Medline

Geinisman Y (1993) Perforated axospinous synapses with multiple, completely partitioned transmission zones: probable structural intermediates in synaptic plasticity. Hippocampus 3:417-433. CrossRef Medline

Germuska M, Saha S, Fiala J, Barbas H (2006) Synaptic distinction of laminar-specific prefrontal-temporal pathways in primates. Cereb Cortex 16:865-875. CrossRef Medline

Girardeau G, Inema I, Buzsáki G (2017) Reactivations of emotional memory in the hippocampus-amygdala system during sleep. Nat Neurosci 20:1634-1642. CrossRef Medline

Gulyás AI, Miettinen R, Jacobowitz DM, Freund TF (1992) Calretinin is present in non-pyramidal cells of the rat hippocampus-I. A new type of neuron specifically associated with the mossy fibre system. Neuroscience 48:1-27. CrossRef Medline

Gulyás AI, Hájos N, Freund TF (1996) Interneurons containing calretinin are specialized to control other interneurons in the rat hippocampus. J Neurosci 16:3397-3411. CrossRef Medline

Hamann SB, Ely TD, Grafton ST, Kilts CD (1999) Amygdala activity related to enhanced memory for pleasant and aversive stimuli. Nat Neurosci 2:289-293. CrossRef Medline

Inman CS, Manns JR, Bijanki KR, Bass DI, Hamann S, Drane DL, Fasano RE, Kovach CK, Gross RE, Willie JT (2018) Direct electrical stimulation of the amygdala enhances declarative memory in humans. Proc Natl Acad Sci U S A 115:98-103. CrossRef Medline

Ito R, Lee AC (2016) The role of the hippocampus in approach-avoidance conflict decision-making: evidence from rodent and human studies. Behav Brain Res 313:345-357. CrossRef Medline

Jensen FE, Harris KM (1989) Preservation of neuronal ultrastructure in hippocampal slices using rapid microwave-enhanced fixation. J Neurosci Methods 29:217-230. CrossRef Medline

Jones EG, Powell TP (1969) Morphological variations in the dendritic spines of the neocortex. J Cell Sci 5:509-529. Medline

Jutras MJ, Fries P, Buffalo EA (2009) Gamma-band synchronization in the macaque hippocampus and memory formation. J Neurosci 29:1252112531. CrossRef Medline

Kamondi A, Acsády L, Wang XJ, Buzsáki G (1998) Theta oscillations in somata and dendrites of hippocampal pyramidal cells in vivo: activity- dependent phase-precession of action potentials. Hippocampus 8:244261. CrossRef Medline

Kawaguchi Y, Katsumaru H, Kosaka T, Heizmann CW, Hama K (1987) Fast spiking cells in rat hippocampus (CA1 region) contain the calciumbinding protein parvalbumin. Brain Res 416:369-374. CrossRef Medline

Khakpai F, Nasehi M, Haeri-Rohani A, Eidi A, Zarrindast MR (2013) Septohippocampo-septal loop and memory formation. Basic Clin Neurosci 4:5-23. Medline

Kjelstrup KG, Tuvnes FA, Steffenach HA, Murison R, Moser EI, Moser MB (2002) Reduced fear expression after lesions of the ventral hippocampus. Proc Natl Acad Sci U S A 99:10825-10830. CrossRef Medline

Klausberger T (2009) GABAergic interneurons targeting dendrites of pyramidal cells in the CA1 area of the hippocampus. Eur J Neurosci 30:947957. CrossRef Medline

Klausberger T, Magill PJ, Márton LF, Roberts JD, Cobden PM, Buzsáki G, Somogyi P (2003) Brain-state- and cell-type-specific firing of hippocampal interneurons in vivo. Nature 421:844-848. CrossRef Medline

Koene RA, Hasselmo ME (2008) Reversed and forward buffering of behavioral spike sequences enables retrospective and prospective retrieval in hippocampal regions CA3 and CA1. Neural Netw 21:276-288. CrossRef Medline

Lacy JW, Yassa MA, Stark SM, Muftuler LT, Stark CE (2010) Distinct pattern separation related transfer functions in human CA3/dentate and CA1 revealed using high-resolution fMRI and variable mnemonic similarity. Learn Mem 18:15-18. CrossRef Medline

Langston RF, Stevenson CH, Wilson CL, Saunders I, Wood ER (2010) The role of hippocampal subregions in memory for stimulus associations. Behav Brain Res 215:275-291. CrossRef Medline

LeDoux JE (1992) Brain mechanisms of emotion and emotional learning. Curr Opin Neurobiol 2:191-197. CrossRef Medline

Lee I, Kesner RP (2004) Encoding versus retrieval of spatial memory: double dissociation between the dentate gyrus and the perforant path inputs into CA3 in the dorsal hippocampus. Hippocampus 14:66-76. CrossRef Medline

Lee I, Yoganarasimha D, Rao G, Knierim JJ (2004) Comparison of population coherence of place cells in hippocampal subfields CA1 and CA3. Nature 430:456-459. CrossRef Medline

Leranth C, Ribak CE (1991) Calcium-binding proteins are concentrated in the CA2 field of the monkey hippocampus: a possible key to this region's resistance to epileptic damage. Exp Brain Res 85:129-136. Medline

Liberzon I, Abelson JL (2016) Context processing and the neurobiology of post-traumatic stress disorder. Neuron 92:14-30. CrossRef Medline

Manns JR, Eichenbaum H (2006) Evolution of declarative memory. Hippocampus 16:795-808. CrossRef Medline

Maren S, Phan KL, Liberzon I (2013) The contextual brain: implications for fear conditioning, extinction and psychopathology. Nat Rev Neurosci 14:417-428. CrossRef Medline

Matsuzaki M, Ellis-Davies GC, Nemoto T, Miyashita Y, Iino M, Kasai H (2001) Dendritic spine geometry is critical for AMPA receptor expression in hippocampal CA1 pyramidal neurons. Nat Neurosci 4:10861092. CrossRef Medline

McDonald AJ, Mott DD (2017) Functional neuroanatomy of amygdalohippocampal interconnections and their role in learning and memory. J Neurosci Res 95:797-820. CrossRef Medline

McNaughton BL, Morris RGM (1987) Hippocampal synaptic enhancement and information storage within a distributed memory system. Cell 10:8.

Medalla M, Barbas H (2009) Synapses with inhibitory neurons differentiate anterior cingulate from dorsolateral prefrontal pathways associated with cognitive control. Neuron 61:609-620. CrossRef Medline

Medalla M, Luebke JI (2015) Diversity of glutamatergic synaptic strength in lateral prefrontal versus primary visual cortices in the rhesus monkey. J Neurosci 35:112-127. CrossRef Medline

Medalla M, Gilman JP, Wang JY, Luebke JI (2017) Strength and diversity of inhibitory signaling differentiates primate anterior cingulate from lateral prefrontal cortex. J Neurosci 37:4717-4734. CrossRef Medline

Megías M, Emri Z, Freund TF, Gulyás AI (2001) Total number and distribution of inhibitory and excitatory synapses on hippocampal CA1 pyramidal cells. Neuroscience 102:527-540. CrossRef Medline

Miettinen R, Gulyás AI, Baimbridge KG, Jacobowitz DM, Freund TF (1992) Calretinin is present in non-pyramidal cells of the rat hippocampus-II. Co-existence with other calcium binding proteins and GABA. Neuroscience 48:29-43. CrossRef Medline 
Miyashita T, Ichinohe N, Rockland KS (2007) Differential modes of termination of amygdalothalamic and amygdalocortical projections in the monkey. J Comp Neurol 502:309-324. CrossRef Medline

Murthy VN, Sejnowski TJ, Stevens CF (1997) Heterogeneous release properties of visualized individual hippocampal synapses. Neuron 18:599612. CrossRef Medline

Nader K, Schafe GE, Le Doux JE (2000) Fear memories require protein synthesis in the amygdala for reconsolidation after retrieval. Nature 406: 722-726. CrossRef Medline

Nakazawa K, Quirk MC, Chitwood RA, Watanabe M, Yeckel MF, Sun LD, Kato A, Carr CA, Johnston D, Wilson MA, Tonegawa S (2002) Requirement for hippocampal CA3 NMDA receptors in associative memory recall. Science 297:211-218. CrossRef Medline

Nava N, Chen F, Wegener G, Popoli M, Nyengaard JR (2014) A new efficient method for synaptic vesicle quantification reveals differences between medial prefrontal cortex perforated and nonperforated synapses. J Comp Neurol 522:284-297. CrossRef Medline

Nicholson DA, Trana R, Katz Y, Kath WL, Spruston N, Geinisman Y (2006) Distance-dependent differences in synapse number and AMPA receptor expression in hippocampal CA1 pyramidal neurons. Neuron 50:431-442. CrossRef Medline

Oya H, Kawasaki H, Howard MA 3rd, Adolphs R (2002) Electrophysiological responses in the human amygdala discriminate emotion categories of complex visual stimuli. J Neurosci 22:9502-9512. CrossRef Medline

Packard MG, Teather LA (1998) Amygdala modulation of multiple memory systems: hippocampus and caudate-putamen. Neurobiol Learn Mem 69:163-203. CrossRef Medline

Pagano RR, Gault FP (1964) Amygdala activity: a central measure of arousal. Electroencephalogr Clin Neurophysiol 17:255-260. CrossRef Medline

Papp OI, Karlócai MR, Tóth IE, Freund TF, Hájos N (2013) Different input and output properties characterize parvalbumin-positive basket and axoaxonic cells in the hippocampal CA3 subfield. Hippocampus 23:903-918. CrossRef Medline

Paré D (2003) Role of the basolateral amygdala in memory consolidation. Prog Neurobiol 70:409-420. CrossRef Medline

Paré D, Collins DR, Pelletier JG (2002) Amygdala oscillations and the consolidation of emotional memories. Trends Cogn Sci 6:306-314. CrossRef Medline

Paré D, Dong J, Gaudreau H (1995) Amygdalo-entorhinal relations and their reflection in the hippocampal formation: generation of sharp sleep potentials. J Neurosci 15:2482-2503. CrossRef Medline

Paz R, Pare D (2013) Physiological basis for emotional modulation of memory circuits by the amygdala. Curr Opin Neurobiol 23:381-386. CrossRef Medline

Pelkey KA, Chittajallu R, Craig MT, Tricoire L, Wester JC, McBain CJ (2017) Hippocampal GABAergic inhibitory interneurons. Physiol Rev 97:16191747. CrossRef Medline

Peters A, Palay SL, Webster HD (1991) The fine structure of the nervous system: neurons and their supporting cells, Ed 3. New York: Oxford UP.

Petrovich GD, Canteras NS, Swanson LW (2001) Combinatorial amygdalar inputs to hippocampal domains and hypothalamic behavior systems. Brain Res Brain Res Rev 38:247-289. CrossRef Medline

Phillips RG, LeDoux JE (1992) Differential contribution of amygdala and hippocampus to cued and contextual fear conditioning. Behav Neurosci 106:274-285. CrossRef Medline

Pierce JP, Lewin GR (1994) An ultrastructural size principle. Neuroscience 58:441-446. CrossRef Medline

Pierce JP, Mendell LM (1993) Quantitative ultrastructure of Ia boutons in the ventral horn: scaling and positional relationships. J Neurosci 13: 4748-4763. CrossRef Medline

Pikkarainen M, Rönkkö S, Savander V, Insausti R, Pitkänen A (1999) Projections from the lateral, basal, and accessory basal nuclei of the amygdala to the hippocampal formation in rat. J Comp Neurol 403:229-260. CrossRef Medline

Pitkänen A, Pikkarainen M, Nurminen N, Ylinen A (2000) Reciprocal connections between the amygdala and the hippocampal formation, perirhinal cortex, and postrhinal cortex in rat. A review. Ann N Y Acad Sci 911:369-391. CrossRef Medline

Poppenk J, Evensmoen HR, Moscovitch M, Nadel L (2013) Long-axis specialization of the human hippocampus. Trends Cogn Sci 17:230-240. CrossRef Medline
Raghavachari S, Lisman JE (2004) Properties of quantal transmission at CA1 synapses. J Neurophysiol 92:2456-2467. CrossRef Medline

Redondo RL, Kim J, Arons AL, Ramirez S, Liu X, Tonegawa S (2014) Bidirectional switch of the valence associated with a hippocampal contextual memory engram. Nature 513:426-430. CrossRef Medline

Ribak CE, Seress L, Leranth C (1993) Electron microscopic immunocytochemical study of the distribution of parvalbumin-containing neurons and axon terminals in the primate dentate gyrus and Ammon's horn. J Comp Neurol 327:298-321. CrossRef Medline

Rosene DL, Van Hoesen GW (1977) Hippocampal efferents reach widespread areas of cerebral cortex and amygdala in the rhesus monkey. Science 198:315-317. CrossRef Medline

Rosene DL, Van Hoesen GW (1987) The hippocampal formation of the primate brain. In: Cerebral cortex (Jones EG, Peters A, eds), pp 345-456. New York, NY: Plenum Publishing Corporation. CrossRef

Rosenmund C, Stevens CF (1996) Definition of the readily releasable pool of vesicles at hippocampal synapses. Neuron 16:1197-1207. CrossRef Medline

Sato W, Kochiyama T, Uono S, Matsuda K, Usui K, Inoue Y, Toichi M (2011) Rapid amygdala gamma oscillations in response to fearful facial expressions. Neuropsychologia 49:612-617. CrossRef Medline

Sato W, Kochiyama T, Uono S, Matsuda K, Usui K, Inoue Y, Toichi M (2013) Rapid and multiple-stage activation of the human amygdala for processing facial signals. Commun Integr Biol 6:e24562. CrossRef Medline

Saunders RC, Rosene DL, Van Hoesen GW (1988) Comparison of the efferents of the amygdala and the hippocampal formation in the rhesus monkey: II. Reciprocal and non-reciprocal connections. J Comp Neurol 271: 185-207. CrossRef Medline

Scharfman HE, Myers CE (2012) Hilar mossy cells of the dentate gyrus: a historical perspective. Front Neural Circuits 6:106. CrossRef Medline

Schlingloff D, Káli S, Freund TF, Hájos N, Gulyás AI (2014) Mechanisms of sharp wave initiation and ripple generation. J Neurosci 34:11385-11398. CrossRef Medline

Sederberg PB, Schulze-Bonhage A, Madsen JR, Bromfield EB, McCarthy DC, Brandt A, Tully MS, Kahana MJ (2007) Hippocampal and neocortical gamma oscillations predict memory formation in humans. Cereb Cortex 17:1190-1196. CrossRef Medline

Seress L, Gulyás AI, Freund TF (1991) Parvalbumin- and calbindin D28kimmunoreactive neurons in the hippocampal formation of the macaque monkey. J Comp Neurol 313:162-177. CrossRef Medline

Seress L, Nitsch R, Leranth C (1993a) Calretinin immunoreactivity in the monkey hippocampal formation-I. Light and electron microscopic characteristics and co-localization with other calcium-binding proteins. Neuroscience 55:775-796. CrossRef Medline

Seress L, Gulyás AI, Ferrer I, Tunon T, Soriano E, Freund TF (1993b) Distribution, morphological features, and synaptic connections of parvalbumin- and calbindin D28k-immunoreactive neurons in the human hippocampal formation. J Comp Neurol 337:208-230. CrossRef Medline

Shin LM, Rauch SL, Pitman RK (2006) Amygdala, medial prefrontal cortex, and hippocampal function in PTSD. Ann N Y Acad Sci 1071:67-79. CrossRef Medline

Sik A, Penttonen M, Ylinen A, Buzsáki G (1995) Hippocampal CA1 interneurons: an in vivo intracellular labeling study. J Neurosci 15:66516665. CrossRef Medline

Stevens CF (2004) Presynaptic function. Curr Opin Neurobiol 14:341-345. CrossRef Medline

Steward O, Scoville SA (1976) Cells of origin of entorhinal cortical afferents to the hippocampus and fascia dentata of the rat. J Comp Neurol 169:347370. CrossRef Medline

Strange BA, Witter MP, Lein ES, Moser EI (2014) Functional organization of the hippocampal longitudinal axis. Nat Rev Neurosci 15:655-669. CrossRef Medline

Suthana NA, Ekstrom AD, Moshirvaziri S, Knowlton B, Bookheimer SY (2009) Human hippocampal CA1 involvement during allocentric encoding of spatial information. J Neurosci 29:10512-10519. CrossRef Medline

Thomson AM (2000) Molecular frequency filters at central synapses. Prog Neurobiol 62:159-196. CrossRef Medline

Timbie C, Barbas H (2014) Specialized pathways from the primate amygdala to posterior orbitofrontal cortex. J Neurosci 34:8106-8118. CrossRef Medline 
Timbie C, Barbas H (2015) Pathways for emotions: specializations in the amygdalar, mediodorsal thalamic, and posterior orbitofrontal network. J Neurosci 35:11976-11987. CrossRef Medline

Tóth K, Eross L, Vajda J, Halász P, Freund TF, Maglóczky Z (2010) Loss and reorganization of calretinin-containing interneurons in the epileptic human hippocampus. Brain 133:2763-2777. CrossRef Medline

Tóth K, Freund TF (1992) Calbindin D28k-containing nonpyramidal cells in the rat hippocampus: their immunoreactivity for GABA and projection to the medial septum. Neuroscience 49:793-805. CrossRef Medline

Trimper JB, Galloway CR, Jones AC, Mandi K, Manns JR (2017) Gamma oscillations in rat hippocampal subregions dentate gyrus, CA3, CA1, and subiculum underlie associative memory encoding. Cell Rep 21:24192432. CrossRef Medline

Urbán Z, Maglóczky Z, Freund TF (2002) Calretinin-containing interneurons innervate both principal cells and interneurons in the CA1 region of the human hippocampus. Acta Biol Hung 53:205-220. CrossRef Medline

VanElzakker MB, Dahlgren MK, Davis FC, Dubois S, Shin LM (2014) From pavlov to PTSD: the extinction of conditioned fear in rodents, humans, and anxiety disorders. Neurobiol Learn Mem 113:3-18. CrossRef Medline

Vaughn JE, Grieshaber JA (1972) An electron microscopic investigation of glycogen and mitochondria in developing and adult rat spinal motor neuropil. J Neurocytol 1:397-412. CrossRef Medline

Vertes RP, Linley SB, Hoover WB (2015) Limbic circuitry of the midline thalamus. Neurosci Biobehav Rev 54:89-107. CrossRef Medline

Wellman LL, Forcelli PA, Aguilar BL, Malkova L (2016) Bidirectional control of social behavior by activity within basolateral and central amygdala of primates. J Neurosci 36:8746-8756. CrossRef Medline

West MJ (2012) Introduction to stereology. In: Basic stereology for biologists and neuroscientists, pp 843-851. New York, NY: Cold Spring Harbor Laboratory.

Witter MP, Amaral DG (1991) Entorhinal cortex of the monkey: V. Projections to the dentate gyrus, hippocampus, and subicular complex. J Comp Neurol 307:437-459. CrossRef Medline

Zeidman P, Maguire EA (2016) Anterior hippocampus: the anatomy of perception, imagination and episodic memory. Nat Rev Neurosci 17:173182. CrossRef Medline

Zikopoulos B, Barbas H (2007) Parallel driving and modulatory pathways link the prefrontal cortex and thalamus PLoS One 2:e848. CrossRef

Zikopoulos B, John YJ, García-Cabezas MÁ, Bunce JG, Barbas H (2016) The intercalated nuclear complex of the primate amygdala. Neuroscience 330: 267-290. CrossRef Medline 